Benevolent Sexism, Attachment, and Chivalry: Examining the Role of Unfulfilled Needs in Contexts of Dependence

By

Vanessa Sieng

\begin{abstract}
A thesis
Submitted to the Victoria University of Wellington

In fulfilment of the requirements for the degree of

Master of Science
\end{abstract}

Victoria University of Wellington 


\begin{abstract}
Previous research demonstrate links between men's and women's endorsement of benevolent sexism and the provision/acceptance of chivalrous behaviours that increase women's dependence on men. Research also shows that men who are relatively more anxiously attached also tend to be more endorsing of benevolent sexism as it facilitates dependence and fulfilment of relational needs. Thus, men's preoccupations with satisfying their relational needs should heighten their tendency to behave chivalrously. This thesis examined whether attachment anxiety moderates the link between individual's endorsement of benevolent sexism and their provision/acceptance of dependency-oriented support-behaviours that emphasise men's high status and women's dependence. This study also tested whether men providing, and women accepting support predicts fulfilment of relational needs. Study 1 and $2(N=354)$ examined links between endorsement of benevolent sexism and dependencyoriented dating behaviours in online samples. Results replicated the existing link between men's endorsement of benevolent sexism and dependency-oriented support, but did not lend support for the moderating role of attachment anxiety. In Study 3, romantic couples $(N=158)$ discussed personal goals with one another and coders observed levels of dependency-oriented support provision and acceptance. The relationship between benevolent sexism and dependency-oriented support for men was once again replicated. Novel interactions also emerged which suggests that holding derogatory beliefs about women may also motivate men's dependency-oriented support giving. Predictions about the role of attachment anxiety and need fulfilment produced unexpected findings demonstrating that it may be a lack of avoidant rather than attachment anxiety that moderates the relationship between benevolent sexism and dependency-oriented support. These studies illustrate that chivalrous, dependency-oriented behaviours cannot be examined in isolation from beliefs about gender roles, relational schemas, and context.
\end{abstract}




\section{Benevolent Sexism, Attachment, and Chivalry: Examining the Role of Unfulfilled Needs in Contexts of Dependence}

It is often expressed that chivalry is dead — an archaic set of romantic behaviours, framed as something heterosexual women "want" and heterosexual men "should provide"but ideas of chivalry are not dead. Ambivalent sexism theory describes benevolent sexism as a modern form of sexism that has an appealing and subjectively positive appearance, including views that women should be protected, provided for, and cherished by men (Glick \& Fiske, 1996). However, benevolent sexism is subtly harmful because these romanticsounding beliefs position women as lacking the competence and agency to fend for themselves (Glick \& Fiske, 1996). Men who endorse benevolent sexism tend to behave in ways that are more paternalistic or patriarchal forms of "chivalry" (Grabe et al., 2006; Viki et al., 2003; Leone et al., 2020). Chivalrous acts include protecting women from harm (e.g., sexual assault; Leone et al., 2020; Viki et al., 2002; Viki et al., 2005), providing for women financially (e.g., paying on a date; Viki et al., 2003), and offering women help in traditionally "masculine" domains (e.g., help with cars and computers; Shnabel et al., 2016). Whilst these behaviours may appear polite and considerate, chivalry is only offered to women who are seen as submissive, sexually conservative, and nurturing (Viki \& Abrams, 2002; Viki et al., 2005). Furthermore, emphasising men's responsibility to protect traditional women simultaneously implies women's weakness, and their lack of agency outside the domestic sphere (Glick \& Fiske, 1996; Hammond \& Overall, 2015; Moya et al., 2007; Shnabel et al., 2016). Finally, the care and chivalry offered by men to "traditional women" is employed to rationalise the withdrawal of reverence and protection when women violate traditional gender roles, such as derogating or blaming victims of sexual assault (Abrams et al., 2003; Viki et al., 2002; Viki et al., 2005). In sum, chivalrous acts are theorised to be incorporated into gender inequality and sexist ideologies. 
In the current research we extend understanding of the link between men's benevolent sexism and provision of paternalistic chivalry by investigating an underlying mechanism: The motivation to fulfil relational needs. Specifically, I argue that a greater preoccupation to fulfil relational needs heightens men's tendency to behave chivalrously towards women. Similarly, greater preoccupations to fulfil relational needs should heighten women's tendency to be more accepting of men's chivalry. Research examining women's reactions and appraisals of men's chivalry suggests that women tend to respond positively to chivalry when it is framed as protection. Moreover, women who endorse benevolent sexism tend to request chivalrous forms of help from men to achieve goals (Moya et al., 2007; Shnabel et al., 2016). Thus, in addition to understanding the conditions under which men are more likely to behave chivalrously, we also investigate the conditions under which women are more likely to accept men's chivalry. In the following sections I further discuss the theoretical links between benevolent sexism and chivalry (Glick \& Fiske, 1996), and draw from attachment theory (Hazan \& Shaver, 1987) to argue that the mechanism underlying this link is the preoccupation to satisfy core relationship needs. I end by describing three studies that test my predictions in relevant contexts in which chivalrous behaviours emerge, including discussion of personal goals and evaluation of behaviours on romantic dates.

\section{Principles of Ambivalent Sexism Theory}

Ambivalent sexism theory states that the content of sexism can be separated into two coexisting ideologies (Glick \& Fiske, 1996). The first ideology, hostile sexism-overtly antagonistic and demeaning attitudes and behaviours-encompasses beliefs that women are weak and subordinate compared to men (dominative paternalism), women lack the traits needed to be strong authoritative leaders (competitive gender differentiation), and women are temptresses who use sex to manipulate men and gain power (heterosexual hostility; Glick \& Fiske, 1996). The second ideology, benevolent sexism—covertly patronising and 
condescending attitudes and behaviours — encompasses beliefs that men should provide for and protect women as they are the weaker sex (protective paternalism), women are better caretakers as they have greater sensitivity and emotional competency compared to men (complementary gender differentiation), and that being in relationships with women satisfies the need for intimacy and psychological closeness (heterosexual intimacy; Glick \& Fiske, 1996).

Hostile sexism and benevolent sexism have opposing evaluative tones, but both undermine gender equality. While hostile sexist remarks such as "women are less competent than men" outright derogates women, benevolent sexist remarks such as "a woman's love completes men" appears to be positive and even romantic (Ambivalent Sexism Inventory; Glick \& Fiske, 1996, p. 512). Hostile and benevolent sexism both operate upon beliefs that women are inferior to men and should be kept in their place, regardless of whether individuals perceive the messages to be positive or not. The two forms of sexism go hand-inhand as a means to avoid overt conflict between men and women over the unequal access to structural power in society, and for men and women to foster close intimate bonds with one another (Jackman, 1994). Studies support this central tenet of ambivalent sexism theory, by showing that people who endorse hostile sexism will also tend to endorse benevolent sexism, a finding that is consistent across many nations and cultures (Glick \& Fiske, 1996; Glick et al., 2000; Glick \& Fiske, 2001). Thus, the endorsement of both hostile and benevolent sexism—while seemingly opposite in tone — ultimately perpetuates gender inequality, but functions to facilitate mutual romantic relationships between men and women (Glick \& Fiske, 1996).

Research has illustrated many negative consequences of endorsing hostile sexism, including harm across societies and harm within relationships. Specifically, hostile sexism negatively affects women's advancement in society and men's fulfilment of intimacy in the 
relational sphere. For example, greater endorsement of hostile sexism in the workforce predicts greater discrimination towards women applying for managerial roles (Masser \& Abrams, 2004). Individuals who endorse hostile sexism also have a greater tendency to justify imbalances such as the gender pay gap, despite the aforementioned bias shown in the workplace (Connor \& Fiske, 2019). Such behaviours arise because women occupying positions of power are in opposition with the notion that men are more agentic and competent compared to women. Within the relationship sphere, men's endorsement of hostile sexism predicts a greater tendency to perceive partners' actions as more negative, behave more negatively and aggressively towards their partners, and predicts a decrease in relationship satisfaction (Cross \& Overall, 2018; Cross \& Overall, 2019; Hammond \& Overall, 2013). Negative and aggressive behaviours within intimate relationships are a product of men's concerns with holding power, and their tendency to believe that women are manipulative. Therefore, the endorsement of hostile sexism not only jeopardises women's chances of succeeding in society, but it also undermines men's ability to establish intimacy and closeness with their partners in romantic relationships.

Similarly, the endorsement of benevolent sexism also has harmful effects, particularly for women in the workplace. Benevolently sexist remarks directed toward women are associated with declines in women's interest in gaining personal power, independence, pursuit of higher education and high-status jobs, women's performance in cognitive tasks, their perceived competency, self-esteem, and self-efficacy in the workplace (Dardenne et al., 2007; Jones et al., 2014; Rudman \& Heppen, 2003). By echoing the idea that women are less agentic, less competent, and more valued for their feminine qualities, women tend to be more doubtful of their abilities, subsequently harming their progress and success in society. The harms of benevolent sexism are twofold, as it is more subtle at perpetuating gender inequalities compared to the overt expressions of hostile sexism. For example, women tend to 
misinterpret accounts of benevolent sexism that they have encountered, by underestimating the patronising and condescending tones that benevolent sexism expresses (Bosson et al., 2010; Rudman \& Fetterolf, 2014). Women who explicitly reject the romantic ideals associated with benevolent sexism do not demonstrate the same rejection at the implicit or subconscious level (Rudman \& Heppen, 2003). Profiles of men who endorse benevolently sexist beliefs (e.g., men who believe women should be adored, cared for, and protected) are also appraised more favourably than profiles of men endorsing hostile sexist beliefs, as they appear to be romantic and chivalrous (Kilianski \& Rudman, 1998). Moreover, both men and women do not tend to view benevolent sexism as damaging to women, and often perceive such beliefs to contrast and oppose hostile sexism altogether, despite both ideologies playing a hand at maintaining inequalities between men and women (Rudman \& Fetterolf, 2014). Thus, while the attitudes and behaviours that make up benevolent sexism may appear to be benign and are often romanticised, they are silently undermining women's independence and personal power gains at a societal level.

At the interpersonal level, the endorsement of benevolent sexism is theorised as a means of fostering heterosexual closeness within intimate relationships. For example, men who endorse benevolent sexism tend to use "soft" (i.e., less overtly hostile) strategies, such as being more understanding of women's perspectives when it comes to relationship matters, offering direct help, advice, or solutions, and employing protective reasoning to restrict nontraditional female behaviours (Hammond \& Overall, 2015; Moya et al., 2007; Overall et al., 2011). Utilising soft strategies can benefit men's maintenance of power and status as the "protector" and "provider", and charm women into responding in ways which creates a sense of intimacy which cannot be attained by using expressively hostile strategies (e.g., criticising, showing dominance, demanding changes; Overall et al., 2011). Men's endorsement of benevolent sexism results in a range of behaviours that perpetuates the gender roles and 
inequalities but also facilitates intimacy and fosters greater psychological closeness. In line with ambivalent sexism theory, this intimacy is a core relational need that men strive to satisfy by using soft strategies associated with benevolent sexism (i.e., heterosexual intimacy; Glick \& Fiske, 1996).

The central principle of ambivalent sexism theory argues that hostile and benevolent forms of sexism coexist. By simultaneously endorsing the more subjectively benevolent form of sexism, men can "disarm" women and continue to uphold the idea that they are the weaker, less competent, and ultimately inferior sex without the overt antagonistic tones that hostile sexism expresses (Glick \& Fiske, 1996; Jackman, 1994). In doing so, the status-quo is maintained; men continue to hold their structural power in institutions outside the household, and are thought of as protectors and providers for women, whereas women have greater power in the domestic sphere but are confined to feminine roles such as housewives and caretakers. Although the consequences of endorsing benevolent sexism may seem direparticularly for women - there are many reasons why it is a widely accepted ideology. In the next section, I discuss these reasons as to why men and women endorse benevolent sexism to further understand the contexts in which men's chivalry is prompted.

\section{Why do People Endorse Benevolent Sexism?}

Benevolent sexism enhances men's structural power. Previous research demonstrates the link between men's concerns with/entitlement to power and their endorsement of benevolent sexism. That is, men who are more concerned with maintaining social status, and felt more psychologically entitled to social power, status, and resources tended to more strongly endorse benevolent sexism (Hammond et al., 2013; Leone et al., 2020). One way benevolent sexism facilitates men's structural power is by framing men as more competent than women. For example, individuals who endorse benevolent sexism perceive men to be more competent compared to women (Delacollette et al., 2013; Ramos et al., 2018). 
Ascribing men with competence reinforces support and justification of men's dominance in society, and promotes behaviours that maintain the gender status-quo. For example, individuals who endorse benevolent sexism tend to prefer male political candidates, and this link is mediated by system justifying beliefs (e.g., men are more capable and thus, make better leaders; Russo et al., 2014). Another way that benevolent sexism enhances men's structural power is through the use of paternalistic strategies and behaviours directed towards women. Jackman (1994) describes such soft strategies to be more persuasive at influencing women compared to explicitly hostile and antagonising strategies. For example, in a study by Fraser and colleagues (2015), it was shown that endorsing benevolent sexism mitigates the association between dominance orientations and people's opposition against gender-based affirmative action (e.g., women's right to work, education, etc.). While this finding may seem paradoxical, the view that women cannot progress in society without the help and assistance of men is patronising and condescending in nature. Thus, endorsing benevolent sexism is a covert and effective means of maintaining men's dominance in society, and undermining women's structural power.

Within the relational sphere, research also demonstrates that men's endorsement of benevolent sexism facilitates access to intimacy. One of the core principles underlying ambivalent sexism theory is the notion that men crave a need for intimacy, and such intimacy can only be forged and satisfied within relationships (Glick \& Fiske, 1996). Intimacy is defined as experiencing psychological closeness, connection, and bonding (Glick \& Fiske, 1996; Sternberg, 1997). Behaviours that are linked to benevolent sexism are often covert strategies to foster intimacy with women, and appear seemingly charming and chivalrous. For example, research has shown that when men endorse benevolent sexism, they tend to be more open and less hostile during conflict discussions, which led to more successful resolutions for couples (Overall et al., 2011). Men also tend to provide direct assistance or solutions when 
their female counterparts require help, which maintains women's dependence on men but appears as a chivalrous act (Hammond \& Overall, 2015; Shnabel et al., 2016).

In return, men receive support from female partners in a way that establishes the relationship as a secure base while encouraging active exploration, which facilitates men's feelings of intimacy and regard (Hammond \& Overall, 2015). Men's adoption of a "protector" role in relationships is also perceived as a positive act by women, as they feel protected, cherished, and important to their partners, despite having restrictions enforced on their behaviours by men (Moya et al., 2007). Moreover, women perceive men who endorse benevolent sexism to be more attractive due to the perceived investments benevolently sexist men bring to the relationship (e.g., protection, provision of resources, commitment to relationship; Gul \& Kupfer, 2019). Thus, men's desire for intimacy fulfilment cannot be facilitated by overtly patronising and demeaning women, but rather cherishing their value as traditional women who need to be protected and cared for.

Although benevolent sexism reinforces women's subordination within society, it also rewards women who abide by traditional feminine roles with benefits. These benefits are outlined by Glick and Fiske (1996) and include protection and reverence from male partners, and the provision of resources that women may not have complete access to (unlike men who have a societal advantage). Once it is clear that men's endorsement of benevolent sexism comes with said benefits, women too tend to endorse benevolent sexism (Hammond et al., 2016). Hammond et al. (2013) found that women who feel a greater sense of entitlement to these benefits tend to more strongly endorse benevolent sexism and this endorsement increased over time; consistent with the notion that endorsing benevolent sexism is linked to perceived benefits in the relational sphere. Women also find men who endorse benevolent sexism more attractive as a potential partner, as benevolent sexism expresses the promises of these benefits to facilitate security, protection, provision of resources, and commitment to the 
relationship (Cross \& Overall, 2018; Gul \& Kupfer, 2019). This finding holds despite women being able to detect the condescending and patronising tones that stem from benevolently sexist beliefs, demonstrating that the perceived benefits of benevolent sexism outweigh the costs to women's independence and progress in society (Gul \& Kupfer, 2019). The common theme across these studies is the need for women to confirm their partners' investment to the relationship. That is, women are preoccupied with what benefits they reap (when giving up some of their independence), and therefore, seek signals from men that indicate they are willing to give in return. Thus, ceding some degree of independence and autonomy facilitates women's access to such benefits and foster a secure relationship base (Viki et al., 2003).

Benevolent sexism also offers benefits to women experiencing inequality. In a crosscultural study of ambivalent sexism, Glick et al. (2000) consistently found that in all nations sampled, men who tended to endorse hostile sexism also tended to endorse benevolent sexism, and women tended to reject hostile sexism but endorse benevolent sexism. While it may not be surprising that women tend to accept the more benevolent form of sexism due to its subtlety, a novel finding demonstrated that women from nations with high inequalities tended to endorse benevolent sexism to a greater degree than women from nations with lesser inequalities (Glick et al., 2000). Extending Jost and Banaji's (1994) system justification theory, Glick and colleagues (2000) explain this effect by highlighting the many alluring benefits that benevolent sexism promises to women. Women often endorse benevolent sexism due to benefits such as gaining men's protection, reverence, and provision of resources which seemingly offsets the structural power men hold in society. This gives the illusion that gender relations are just and fair, which has been linked to greater subjective wellbeing and life satisfaction (Connelly \& Heesacker, 2012; Hammond \& Sibley, 2011; Jost \& Kay, 2005; Napier et al., 2010). In countries where inequalities are greater and men have distinctly more structural power, women are more motivated to gain men's protection, 
reverence, and provision of resources. Endorsing benevolent sexism and believing that women should be protected, revered, and provided for is a means for women to reap the benefits in such unequal circumstances (Glick et al., 2000). By maintaining these structures and roles, men and women - especially women living in countries where inequality is salient—are benefitting from the endorsement of benevolent sexism.

In sum, according to the ambivalent sexism literature, men's endorsement of benevolent sexism functions to gain influence over women (thereby lessening women's structural power within society) by promising protection and reverence, and facilitate men's intimacy and satisfy their need for closeness. By contrast, women's endorsement of benevolent sexism is theorised to subtly reinforce their subordination within society, but rewards them for adopting traditional roles and traits, and allow them to reap the benefits in societies marked by inequality. To further understand how (and under what contexts) benevolent sexism is linked to men's chivalry, we must first focus on how this chivalry behaviourally manifests within intimate relationships. One particular finding that has been consistently reproduced in the literature is men's chivalry during cross-gender support/helping scenarios. In the next section, I discuss previous research that links benevolent sexism to chivalrous behaviour in social support contexts.

\section{How Does Benevolent Sexism Manifest?: Benevolent Sexism and Chivalrous (Dependency-Oriented) Support}

Chivalry refers to a set of socially acceptable behaviours characterised by extreme politeness, courteousness, and consideration (Viki et al., 2003; Viki et al., 2005). Chivalrous behaviours are often marked by power dynamics between men and women, and is often used to refer to men's "gentle treatment" of women (Moulds, 1980). While men's chivalry is seemingly beneficial for women, it comes at the price of implied inferiority at the social level (Moulds, 1980). That is, women are seen as weak and defenceless and thus, in need of 
guidance, assistance, or support from men (Moulds, 1980). Common examples of chivalry include men providing for women financially, offering help in masculine domains, and protecting women from harm (Leone et al., 2020; Shnabel et al., 2016; Viki et al., 2003). These chivalrous acts are labelled "support behaviours" because they occur in supportrelevant contexts (i.e., when help is needed or perceived to be needed) rather than because they are supportive (see Newsom et al., [2005] on negative support behaviours such as unwanted advice, intrusions, unsympathetic/insensitive behaviour, and failure to provide needed help). Indeed, chivalry represents a form of support behaviour that ultimately detracts from women's agency and competence. In this section I will further discuss specific types of social support and how chivalry can manifest as a support behaviour.

A majority of research on social support highlights its many benefits. Receiving social support is beneficial in and of itself, and when it is used as a protective strategy to buffer adverse events and stressors in one's life (Cohen \& Wills, 1985). For example, social support enhances positive coping mechanisms for individuals with severe mental illnesses (Davis \& Brekke, 2014), and has been linked to lower mortality rates and improved physical health markers (Holt-Lunstad et al., 2010; Reblin \& Uchino, 2008; Uchino). Furthermore, individuals in romantic relationships report greater wellbeing than those that are single, and this relationship is mediated by perceived social support (Adamczyk \& Segrin, 2015; Stronge et al., 2019). Other similar findings show that intimacy also confers health benefits to individuals through social support, and social support can enhance relationship satisfaction (Cramer, 2007; Reis \& Franks, 1994). Social support is thus, a central component of romantic relationships that can enhance an individual's health and wellbeing, as well as the health and wellbeing of the relationship as a whole. Examining support behaviours within intimate relationships-for example, during couples conversations about goal pursuits or in support behaviours displayed during romantic dates - can then shed light on what types of support 
individuals may utilise and how these behaviours may function to fulfil relational needs for individuals.

Although social support in general confers benefits to its recipients, not all support behaviours are uniform. Social support researchers examine the different types of helping behaviour rather than the presence versus absence of help, and views help seeking as an inherent marker of dependence, weakness, and incompetence (Nadler \& Chernyak-Hai, 2014; Weiner, 1980). Nadler (1997) differentiates between two types of support that can be given to people in times of need; namely, autonomy-oriented support and dependency-oriented support. While autonomy-oriented support is a type of support that gives the support recipient necessary tools and encouragement to achieve tasks and resolve issues on their own, dependency-oriented support is support that views the support recipient as weak and in need of guidance, which often manifests as direct instruction and taking over the task/issue at hand altogether. As such, people tend to give low-status help seekers dependency-oriented support. While the act of seeking support is perceived to be a sign of dependence, weakness, and/or incompetence on the part of the help seeker, the act of providing support can either facilitate the help seeker's autonomy, or take advantage of the help seeker's weaknesses to render them dependent on the help provider.

Individuals who tend to seek and receive dependency-oriented support tend to experience more negative consequences, despite it being a "support behaviour". Those seeking and receiving this type of support, for example, tend to be over-reliant on assistance from others in times of need, experience less positive affect, vitality, and self-esteem compared to individuals who tend to seek and receive autonomy-oriented support (Nadler, 1997; Weinstein \& Ryan, 2010). Despite such negative implications, people still accept and provide others with dependency-oriented support both within and outside of intimate relationships. Nadler (2002) argue that dependency-oriented support is a tool for groups with 
more power to create and maintain others' dependence on them, and establish dominance over weaker groups, who present themselves as helpless and less competent when seeking help. Within heterosexual romantic relationships, traditional beliefs that men are more autonomous and competent should facilitate dependency-oriented support provision by men, and directed towards women who are traditionally believed to be less autonomous and competent in support scenarios. These dependency-oriented behaviours may even be classed as chivalry, and thus, seemingly harmless to women who are often on the receiving end of such support. For example, when traditional men (i.e., more strongly endorsing of benevolent sexism) are asked to offer advice to their female partners about job opportunities that are potentially dangerous, they will often assume the role of a "protector" and use protective reasoning to dissuade their partners from advancing their careers (Moya et al., 2007). In the context of dating, typical courtship behaviours such as men paying for dinner, men protecting women from other men, and men taking care of planning for dates can be classed as support behaviours that render women dependent on men, but have romantic undertones (Leone et al., 2020; Viki et al., 2003). Thus, while receiving dependency-oriented support may have negative consequences, its chivalrous tones masks the inherent paternalism for women, and functions as an effective strategy that traditional men use to elicit women's dependence within heterosexual romantic relationships.

The hypothesis that traditional men should offer their romantic partners more dependency-oriented support was supported in a study by Hammond and Overall (2015). During the study, heterosexual couples took turns describing and discussing their personal goals whilst being video-recorded in a lab room. The researchers were interested in whether individual's endorsement of benevolent sexism were linked with different support strategies and the functions these different types of support may have for individuals in relationships. The results of the study showed that men who more strongly endorsed benevolent sexism 
tended to provide women with more dependency-oriented support, by offering their partners direct advice and instruction, telling them things that they should be doing, and neglecting their partner's abilities to pursue personal goals on their own. Moreover, women who more strongly endorsed benevolent sexism tended to provide men with more relationship-oriented support, by showing care and affection towards their partners, encouraging their personal goal pursuits, and ensuring that the relationship is a secure and safe base for personal exploration. Consequently, men tend to perceive greater intimacy and regard following their partners' provision of relationship-oriented support, and women tend to feel less competent following their partners' provision of dependency-oriented support. In sum, men who believe they should be protectors and providers offer dependency-oriented support, and women who believe that they should be caring and nurturing in their relationships offer their partners' relationship-oriented support, as a means to fulfil men's intimacy needs despite declines in women's self-rated competence.

Similarly, in a study by Shnabel and colleagues (2016) the association between benevolent sexism and dependency-oriented support was also found in a sample of noncoupled participants. The study involved participants reading hypothetical support scenarios (e.g., parking a car, performing computer functions, solving equations) where men were in the position of providing, and women in the position of receiving support. Shnabel et al. (2016) found that men who more strongly endorsed benevolent sexism tended to choose to directly assist women in support scenarios, compared to offering women instructions on how to solve problems themselves or not intervening. Women who more strongly endorsed benevolent sexism also tended to seek direct help from men in support scenarios, compared to asking for instructions on how to independently solve tasks or not asking for help at all. These patterns were also replicated when participants were merely exposed to benevolently sexist remarks (e.g., "Women should be cherished and protected by men"), such that men 
who were exposed to benevolent sexism tended to offer women more dependency-oriented support, and women who were exposed to benevolent sexism tended to seek more dependency-oriented support from men. More interestingly, these associations only held in cross-gender interactions compared to same-gender interactions, indicating that the function dependency-oriented support is to maintain women's dependence on men under the guise of chivalry. Men's direct assistance, subtly reinforces women's subordination and their lack of competency, but is often sought by women and even appraised positively (see Moya et al., 2007) as it communicates men's care and protection.

Links have also been demonstrated between men's adherence to masculine norms and endorsement of benevolent sexism, and their engagement in bystander behaviour (a form of chivalry) directed towards women. In a study by Leone et al. (2020) men who were recruited for the study completed questionnaires measuring their endorsement of benevolent and hostile sexism, their adherence to traditional masculine norms (e.g., showing toughness, flaunting status), and reports of their own bystander behaviour at parties/social gatherings within the past two months (e.g., making sure women don't leave parties intoxicated and alone). Results indicated a significant interaction between endorsement of benevolent sexism and adherence to masculine norms when predicting prosocial bystander behaviour; stronger adherence to masculine norms predicted greater prosocial bystander behaviour directed towards women, only when men were relatively more endorsing of benevolent sexism. Thus, holding traditional beliefs (especially beliefs that men should protect women) is linked to men's protection of women in social settings, as a means to preserve their sense of social power (Leone et al., 2020).

One of the central tenets of ambivalent sexism theory states that the endorsement of benevolent sexism confers advantages within heterosexual romantic relationships. In this section I explored one such manifestation of benevolent sexism (i.e., dependency-oriented 
support) that is often overlooked as sexism due to its romantic tones and chivalrous nature. The aforementioned research shows that there is a clear link between men's endorsement of benevolent sexism and their provision of dependency-oriented support, and women's endorsement of benevolent sexism and their acceptance of dependency-oriented support. I also explored research that could shed light on what advantages dependency-oriented support may confer for those providing and accepting it. One of the main advantages of providing and accepting dependency-oriented support is the facilitation of intimacy and thus, the fulfilment of relational needs. Preoccupations with fulfilling such needs should therefore, motivate men and women to provide and accept dependency-oriented support (respectively). However, this theoretical claim has yet to be empirically tested. In this final section, I discuss previous research that links individuals' preoccupations with fulfilling relational needs to their endorsement of benevolent sexism by linking attachment theory.

\section{What Heightens Dependency-Oriented Support Provision and Seeking?: Benevolent}

\section{Sexism and Fulfilment of Relational Needs}

If preoccupations with fulfilling relational needs explains why traditional men (i.e., those who more strongly endorse benevolent sexism) act chivalrously (i.e., provide their partners with dependency-oriented support), we should explore patterns of behaviour that distinguish men with a greater preoccupation versus less preoccupation with fulfilling relational needs. Attachment theory is a framework that explains avoidance and approach behaviours within social relationships, stemming from experiences in early childhood (Ainsworth \& Bell, 1970; Bowlby, 1999). From infancy, individuals are born with an innate biological system that aids in maintaining closeness and proximity to primary caregivers to satisfy core survival needs (Bowlby, 1999). Caregivers' responsiveness to these needs ultimately informs inner working models (how reliable oneself is in meeting these needs, and how reliable others are in meeting these needs) and how individuals react accordingly 
(Gillath et al., 2016). Attachment theory was later adapted to examine these avoidance approach behaviours within adult romantic relationships, and how they can satisfy the need for intimacy that arises post-adolescence (Hazan \& Shaver, 1987; Morris, 1982). Three main profiles - termed attachment styles - are identified and used commonly in both the attachment and intimate relationship literature. Individuals higher in attachment avoidance tend to seek independence and autonomy within their close relationships (Hazan \& Shaver, 1987). In contrast, individuals higher in attachment anxiety are afraid of losing romantic partners, and are preoccupied with maintaining a high degree of closeness within their romantic relationships (Hazan \& Shaver, 1987). Individuals low in both attachment avoidance and attachment anxiety are termed as being relatively more secure, available, and able to give and/or receive support and care in their relationships during times of need (Hazan \& Shaver, 1987).

Attachment theory illustrates how relational needs (such as intimacy and security) are particularly salient for individuals higher in attachment anxiety. Individuals who are relatively higher in attachment anxiety are typically fearful of rejection and abandonment, often "smother" their partners, are intensely passionate, and idealise romantic relationships to maintain a sense of felt security and foster intimacy within their relationships (Hazan \& Shaver, 1987). Research supports such theoretical claims, with findings demonstrating that more anxiously attached individuals tend to seek out relationships for the purpose of fulfilling their personal intimacy needs (Snapp et al., 2014), and often overestimate how much time, affection, and self-disclosure is needed to form close bonds with intimate others (Hudson \& Fraley, 2017). Similarly, more anxiously attached individuals also desire deep committed relationships with their partners compared to individuals who are relatively more avoidant and securely attached (Feeney \& Noller, 1990). Individuals who are more anxiously attached tend to want to be in committed relationships due to the perceived benefits relationships 
bring, as well as to avoid the costs of relationship dissolution (Dandurand et al., 2013). This is informed by a working model where anxious individuals have negative views of their own abilities to meet their core needs and more positive views of others' abilities to fulfil them (Gillath et al., 2016). Individuals who are relatively higher in attachment anxiety have greater needs for intimacy and security, which makes the benefits of staying and costs of leaving the relationship more salient, and may lead to the maintenance of unsatisfactory relationships in some cases (Dandurand et al., 2013; Davila \& Bradbury, 2001). Facilitating intimacy and security as a means to satisfy core relational needs is an especially important goal for more anxiously attached individuals as it brings a sense of acceptance and attenuates fears of abandonment (Tran \& Simpson, 2009). Thus, attachment theory highlights the salience of relational need fulfilment to those individuals who are more anxiously attached, as a means to avoid fears of abandonment in their romantic relationships.

Anxious attachment and general preoccupations with fulfilling relational needs are also linked to traditional relationship beliefs such as men needing a woman's love to "feel complete" (Glick \& Fiske, 1996). Indeed, a recent meta-analysis shows that people relatively higher in attachment anxiety, and thus, people who are more preoccupied with fulfilling relational needs, consistently report stronger endorsement of benevolent sexism (Fisher \& Hammond, 2019). Individuals who often seek reassurance about their partner's love and commitment to feel intimate and secure often idealise their romantic partners and romantic love in general, which is in line with the benevolently sexist ideology that heterosexual romance is vital for a feeling of completeness (Glick \& Fiske, 1996; Hart et al., 2012). Thus, existing cross-sectional evidence indicates that people with a greater preoccupation to fulfil relational needs tend to endorse benevolent sexism more strongly.

Previous research has also identified strong, positive links between anxious attachment and dependence (Alonso-Arbiol et al., 2002; Cantazaro \& Wei, 2010; Lowyck et 
al., 2008). Relatively more anxiously attached individuals tend to crave dependency, as this satisfies feelings of closeness, security, and intimacy within romantic relationships (Overall \& Cross, 2019). While seeking ways to increase dependence within relationships may alleviate concerns of rejection and abandonment for more anxiously attached individuals, they may do so in maladaptive ways such as inducing guilt in partners (Overall et al., 2014). Accordingly, anxiously attached individuals' support behaviours may be effective in garnering a sense of dependence and fulfilling needs but can be detrimental to the recipient of this dependency-oriented support as it implies a lack of autonomy and competence. Thus, men who hold beliefs that women should be cared, protected for, and are needed to feel complete in a relationship, may provide women with dependency-oriented support to satisfy relational needs, especially when they are more anxiously attached as motivations to meet these needs are heightened. Similarly, women who hold the belief that men should be protectors and providers may be more accepting of dependency-oriented support especially when they are more anxiously attached, as this is a means to both satisfy relational needs and alleviate abandonment concerns.

In the previous section, I introduced dependency-oriented support behaviours as one way of fulfilling such needs; however, the theory that traditional relationship beliefs (i.e., the endorsement of benevolent sexism) heightens men's provision of dependency-oriented support when men are more preoccupied with meeting these needs has been largely untested. Furthermore, more anxiously attached individuals who are concerned with meeting their own relational needs should be more inclined to provide their partners with more dependencyoriented support to satisfy these needs. There are also theoretical advantages of men's provision and women's acceptance of dependency-oriented support, which include reinforcing men's competence and authority, women's access to men's protection and care, and most importantly facilitating secure, intimate relationships. Thus, men and women who 
endorse benevolent sexism should be more likely to provide or accept dependency-oriented support, especially when preoccupations with fulfilling relational needs are more salient for the individual. I propose three research aims in the next section to further our understanding of the conditions that moderate the link between people's endorsement of benevolent sexism and dependency-oriented support provision and acceptance.

\section{Linking Benevolent Sexism, Attachment, and Support}

I propose a model, displayed in Figure 1, integrating ambivalent sexism, social support, and attachment theories to further understand the function of dependency-oriented support provision and dependency-oriented support acceptance, and test whether the preoccupation to fulfil relational needs is a key mechanism in the relationship between benevolent sexism and dependency-oriented support. I propose three research aims to test this model. Research aim one examines men's endorsement of benevolent sexism and their endorsement of chivalrous, dependency-oriented support provision. Research aim two examines women's endorsement of benevolent sexism and their acceptance of men's dependency-oriented support. Finally, research aim three examines whether the dependencyoriented support giving/receiving successfully fulfils relational needs for both parties within heterosexual romantic relationships.

\section{Research Aim 1}

Previous research examining the link between men's endorsement of benevolent sexism and support behaviours illustrate that men who more strongly endorse benevolent sexism (i.e., men who hold beliefs that women are weak and therefore in need of help from men who are "natural providers") tend to provide women with more dependency-oriented support (Hammond \& Overall, 2015; Shnabel et al., 2016). Thus, I predict that men who more strongly endorse benevolent sexism will tend to provide their partners with more dependency-oriented support (H1a). 


\section{Figure 1}

Conceptual mediation via moderation model depicting the study hypotheses. I predict men's benevolent sexism should predict greater

dependency-oriented support behaviours, heightened under the condition of greater anxious attachment (H1), which should in turn predict the fulfilment of relational needs (H3). By contrast, women's benevolent sexism should predict greater acceptance of dependency-oriented support, heightened under the condition of greater anxious attachment (H2), which should in turn predict the fulfilment of relational needs (H3).

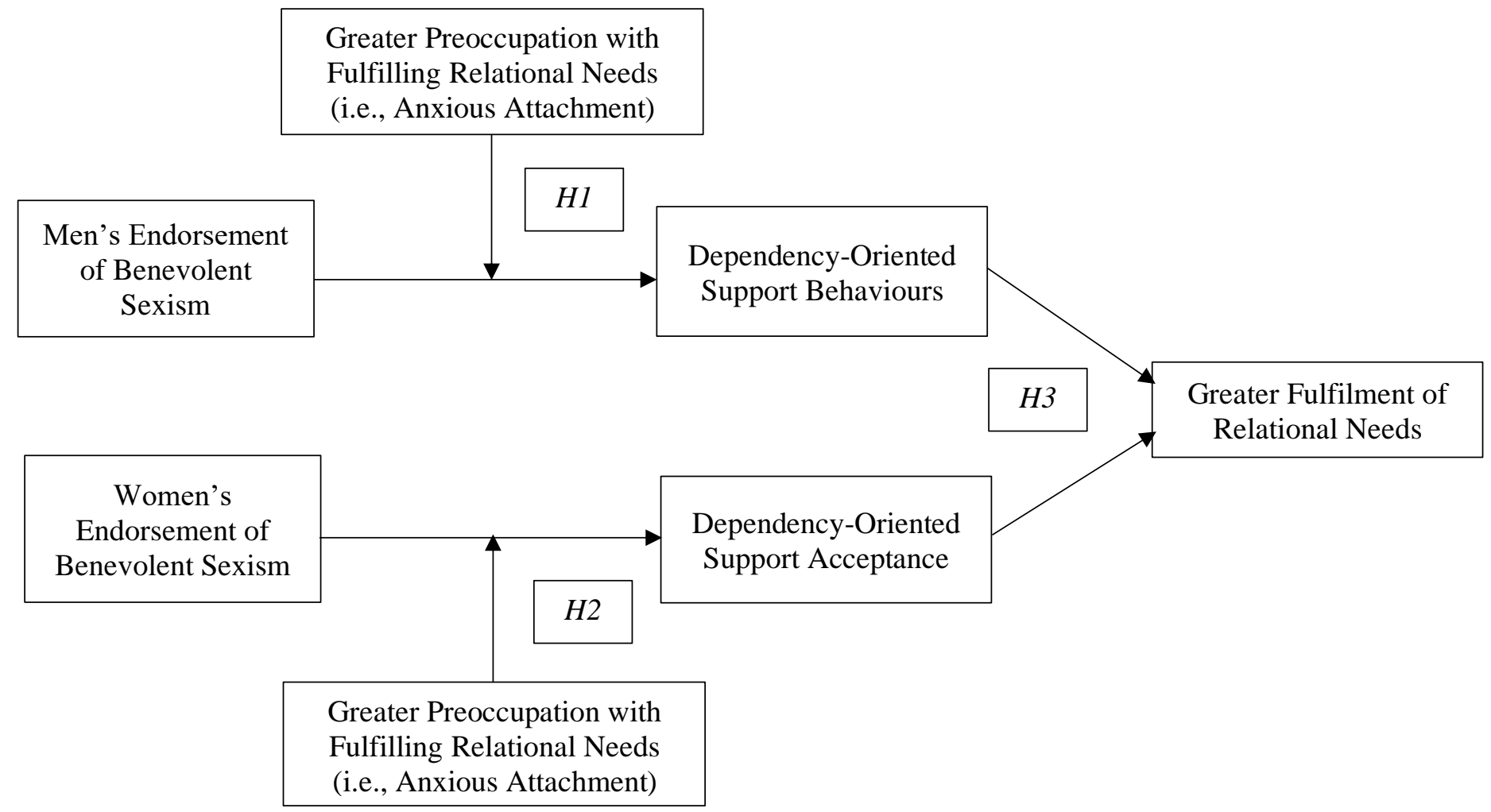


Extending prior research, I address whether this association is heightened when men have relatively greater preoccupation to fulfil relational needs. The tendency to provide dependency-oriented support should be heightened when men-who more strongly endorse benevolent sexism — are also motivated to satisfy core relational needs. Anxiously attached men, who are preoccupied with wanting intimacy, and security within their relationships should then, have greater motivations to satisfy such needs. Coupled with the notion that women complete men and are thus, a core source of intimacy and security, I predict that men who more strongly endorse benevolent sexism and are relatively more anxiously attached will tend to provide their partners with more dependency-oriented support (H1b).

I also predict that by experimentally manipulating men's attachment anxiety (and thereby making salience of one's relational needs more or less pronounced), this will show that preoccupations with fulfilling relational needs (i.e., anxious attachment) causes men who more strongly endorse benevolent sexism to provide their partners with more dependencyoriented support (H1c).

\section{Research Aim 2}

Although sparse, existing research examining women's reactions and appraisals of men's dependency-oriented support provision shows that women who believe that men should be chivalrous, protective, and provide for women in times of need (i.e., women who more strongly endorse benevolent sexism), tend to seek direct advice and solutions from men and respond positively when such suggestions are framed as protective measures (Moya et al., 2007; Shnabel et al., 2016). As such, women who more strongly endorse benevolent sexism should be more accepting of their partner's dependency-oriented support (H2a).

Extending again on this established link, I test whether this association is heightened when women have relatively greater preoccupations with fulfilling relational needs. Whilst research shows that women who endorse benevolent sexism do tend to respond more 
positively and at times seek support that is dependency-oriented, this acceptance of dependency-oriented support should be heightened especially when women are anxiously attached (i.e., they are preoccupied with wanting to forge intimacy and security within their relationships). Thus, I predict that women who more strongly endorse benevolent sexism and are relatively more anxiously attached will tend to accept their partners provision of dependency-oriented support $(\mathrm{H} 2 \mathrm{~b})$.

\section{Research Aim 3}

No research to date has examined whether providing and accepting dependencyoriented support effectively fulfils relational needs. Men who more strongly endorse benevolent sexism and are relatively more anxiously attached should utilise dependencyoriented support as it frames men as chivalrous providers and protectors of women, satisfying the need for closeness and intimacy. Similarly, women who more strongly endorse benevolent sexism and are relatively more anxiously attached should be more accepting of their partner's dependency-oriented support as it echoes the idea that their partners are taking care of them, satisfying the need for increased dependency. Thus, the provision of dependency-oriented support and acceptance of dependency-oriented support should lead to a mutual fulfilment of relational needs ( $\mathrm{H} 3 \mathrm{a}$ and $\mathrm{H} 3 \mathrm{~b}$ respectively).

\section{The Current Study}

The current study investigates whether the relationship between men's and women's endorsement of benevolent sexism and their provision and acceptance of dependencyoriented support (respectively) occurs as a function of fulfilling their relational needs. More specifically, I aim to address whether preoccupations with satisfying relational needs moderates the relationship between men's endorsement of benevolent sexism and their provision of dependency-oriented support (research question 1), and women's endorsement of benevolent sexism and their acceptance of dependency-oriented support (research question 
2). I also address whether men's provision of dependency-oriented support and women's acceptance of dependency-oriented support functions to increase the perception of their relationship security and feelings of intimacy as a consequence of their relational needs being fulfilled (research question 3). Lastly, I aim to establish causality between men's motivation to fulfil relational needs and their provision of dependency-oriented support. I address these pathways in two studies.

The first two studies aims to replicate the finding that men who tend to endorse benevolent sexism more strongly, will also tend to provide their partners with more dependency-oriented support (Hammond \& Overall, 2015; Shnabel et al., 2016). These studies will examine dependency-oriented support behaviours on a broader level, by measuring participants' endorsement of chivalrous dating behaviours — in particular, men's endorsement of chivalrous dating behaviours. Such beliefs often encompass views that men should be agentic, and autonomous, but also courteous and helpful towards women; simultaneously, these views also insinuate women's fragility, defencelessness, and dependence on men for help (e.g., "It is up to the man to decide where a couple are to have a dinner date”; Paternalistic Chivalry Scale; Viki et al., 2003, p. 537). Thus, it is expected that men more endorsing of benevolent sexism will also be more endorsing of chivalrous dating behaviours. Going beyond simple replication, these studies also aim to establish the causality of intimacy needs by manipulating participants' state attachment (secure vs. anxious). I will use an established priming procedure to manipulate how salient men's intimacy needs are versus how secure their relationships are (Finkel et al., 2007). I will then examine men's endorsement of chivalrous behaviours in a dating context, which include providing dependency-oriented support (see Viki et al., 2003). For example, men could endorse the expectation that "a man takes care of the bill on a date". 
The third study will build upon the first by examining observational data from romantic couples as they discuss their personal goals with one another, an established paradigm which inherently places people in the role of a support recipient (when discussing their own goal) and support provider (when discussing their partner's personal goal). Study 2 will test the entirety of the proposed model (see Figure 1) with observations of support discussions between dyads which more accurately reflect individuals' support behaviours in everyday life. I will code these interactions for men's provision of dependency-oriented support using the same coding scheme from Hammond and Overall (2015), and women's acceptance of dependency-oriented support using a devised coding scheme informed by behaviours from Overall et al. (2011). I will assess participants' endorsement of benevolent sexism and participants' motivation to fulfil relational needs (through an attachment measure; Simpson et al., 1996). This study uses a moderation-of-process approach which infers a theoretical mechanism via moderation (Vancouver \& Carlson, 2015). This process allows passive observation of a moderator variable (i.e., attachment) that is thought to be linked to a mediating variable (i.e., fulfilment of relational needs). That is, we can passively observe and measure participants' state attachment (secure vs. anxious) to infer that the fulfilment of relational needs functions to increase tendencies to provide dependency-oriented support, when participants are more anxiously attached.

\section{Study 1}

In the first study, I examined whether experimentally manipulating men's state attachment style affects the extent to which they endorse chivalrous dating beliefs by utilising a priming task to elicit feelings of either attachment anxiety or attachment security. An online study was conducted measuring men's endorsement of sexist beliefs and chivalrous dating beliefs. It was predicted that men who are more endorsing of benevolent sexism will be more endorsing of chivalrous dating behaviours (H1a), and that an anxious attachment should 
strengthen this relationship (H1b). It is also predicted that by priming an anxious attachment, this should cause men who more strongly endorse benevolent sexism to also strongly endorse chivalrous dating behaviours (H1c).

\section{Method}

\section{Participants}

A priori power analysis in $\mathrm{G}^{*}$ Power (Faul et al., 2009) indicated that a medium effect size of $d=0.5$ (Cohen, 1988) in an independent samples t-test with $80 \%$ power $(\alpha=.05$, two tailed) required 64 participants per group (i.e., $N=128$ ). Participants were recruited through Prolific — an online participant recruitment website. One hundred and forty five participants completed the study hosted on Qualtrics. Four participants were excluded for incomplete answers, four were excluded due to no consent given (one participant giving no consent prior to the survey and three participants giving no consent to use data after survey completion), one participant was excluded due to identifying as bisexual, and twelve specified that they had done the word unscrambling task before/were aware of its aims and were excluded. Upon further analysis, three participants exhibited a response bias and were also excluded from the final dataset. From the remaining participants $(N=121)$, all identified as heterosexual males, 65 identified as single, 12 were casually dating, 13 were in a serious relationship, six were living with a partner, and 26 were married. Participants were on average 30 years old $(S D=$ $10.5)$.

\section{Procedure}

All studies were pre-registered on Open Science Framework (OSF). Hypotheses, methodology, and data are openly available on https://osf.io/8mvx3/?view_only= 09e9a11c0bdd4202bd3f37ce8f323920. Participants were screened based on eligibility criteria (heterosexual, male) through Prolific. Eligible participants then gained access to the study hosted on Qualtrics and were presented with an information sheet. Participants were told that 
they could exit the survey at any time, skip questions they did not want to answer, and had the choice to retract their responses at the end. Participants gave consent by agreeing to the terms set out and clicking to the next page. Participants were required to complete the study in one sitting (approximately one hour).

First participants were given questions measuring their endorsement of sexist attitudes, and attachment orientations. To prime attachment orientations, participants were then randomly assigned to be in the secure condition or the anxious condition for the word unscrambling task using Qualtrics' randomiser tool. Participants then completed the priming task disguised as a word puzzle. Participants were then presented with a series of questionnaires, including the dating beliefs scale. Other questionnaires were included in the final version of the study to mask the true nature of the experiment and ensure the manipulation was effective in temporarily changing participants' state attachment. After completing the questionnaires, participants were debriefed and the study aims were revealed. Participants were given $£ 1(\mathrm{GBP})$ for participating in the study at the recommended Prolific hourly rate. Ethical approval for studies was obtained from Victoria University of Wellington's Human Ethics Committee (\#28446).

\section{Materials}

\section{Benevolent and Hostile Sexism}

Participants completed the Ambivalent Sexism Inventory (Glick \& Fiske, 1996). The scale has shown consistently good reliability within and across cultures (Glick et al., 2000). Eleven items assessed benevolent sexism (e.g., "Women should be cherished and protected by men”; -3 = Strongly Disagree, 3 = Strongly Agree) with higher scores indicating greater endorsement of benevolent sexism. Participants also completed 11 items that measured hostile sexism (e.g., “Women seek to gain power by getting control over men”; -3 = Strongly Disagree, 3 = Strongly Agree), which was included in the models as a covariate to examine 
the unique effects of benevolent sexism. Averaged scores for benevolent sexism $(\alpha=.81)$ and hostile sexism $(\alpha=.91)$ displayed good internal reliability.

\section{Attachment Orientations}

Participants' orientations toward fulfilling relational needs was measured as their attachment anxiety using the Adult Attachment Questionnaire (Simpson et al., 1996). Attachment anxiety was assessed using nine items (e.g., "I often worry that my partner(s) don't really love me"; 1 = Strongly Disagree, 7 = Strongly Agree ) with higher scores indicating a greater anxious attachment orientation. Attachment avoidance was also retained as a covariate to examine the unique associations of attachment anxiety, and was assessed using eight items (e.g., "I'm not very comfortable having to depend on romantic partners"; 1 = Strongly Disagree, 7 = Strongly Agree). The questionnaire displayed good internal reliability $(\alpha=.86)$.

\section{Experimental Manipulation of Attachment Orientation}

Participants completed a "scrambled sentence test" procedure which has been used in studies to prime individual's attachment orientations momentarily (see Finkel et al., 2007; Green \& Campbell, 2000). In this priming task, participants are presented with scrambled sentences, containing words that prime particular aspects of attachment orientations, and are asked to unscramble those sentences. For example, "painted, she, door, the" would be unscrambled to create the sentence "she painted the door". In the experimental condition, participants unscrambled sentences that primed attachment anxiety (e.g., "the child felt vulnerable"). In the control condition, participants unscrambled sentences that primed attachment security (e.g., "the child felt protected"). Sentences were adapted from Finkel et al. (2007). Both lists consisted of seven scrambled sentences, including two that were neutral filler sentences. The list can be found in supplementary materials on OSF.

\section{Self-Esteem}


The Rosenberg Self-Esteem Scale (Rosenberg, 1965) was also included in the survey as a manipulation check, to see whether self-esteem scores differed depending on which experimental condition (in the word unscrambling task) participants were assigned to. Ten items measured self-esteem (e.g., "On the whole, I am satisfied with myself"; 1 = Strongly Disagree, 7 = Strongly Agree ) with higher scores indicating greater self-esteem. The scale displayed good internal reliability $(\alpha=.92)$. This measure of self-esteem has been used by Gillath et al. (2006) in a study investigating participant's state attachment orientations. It is predicted that those that are primed to be anxious will have lower self-esteem scores compared to those that are primed to be secure (Gillath et al., 2006).

\section{Endorsement of Chivalrous Dating Behaviours}

Participants were also presented with several statements centred around beliefs and expectations about common chivalrous dating behaviours (i.e., beliefs and expectations of how men and women should behave in a dating context). This scale was used as a proxy for measuring participant's endorsement of men's dependency-oriented support provision towards women in a dating context. Nineteen items were devised and adapted from the paternalistic chivalry items presented in Viki et al. (2003). Items assessed the degree to which participants endorsed traditional dating beliefs (e.g., "I expect that a man takes care of the bill on a date”; 1 = Strongly Agree, 7 = Strongly Disagree . . Higher scores on this scale indicated greater endorsement of chivalrous dating behaviours and thus, greater endorsement of men's provision of dependency-oriented support in a dating context.

To explore the factor structure of the chivalrous dating behaviour scale, the 19 devised items and the 11 benevolent sexism items from the Ambivalent Sexism Inventory (Glick \& Fiske, 1996) were subjected to an exploratory factor analysis in Jamovi (2020). A principal axis factoring extraction method was used in combination with an oblique (promax) rotation. This method was adopted to extract items that did not have high loadings (values > 
.30) on the existing benevolent sexism subscale (see Viki et al., 2003). Factors were extracted with the criterion of eigenvalues larger than one (Kaiser, 1960).

The analysis yielded a three factor solution being the best fit for the data, one being the existing benevolent sexism subscale. Eight items from the chivalrous dating behaviour scale loaded highly onto the benevolent sexism subscale (ranging from .34 to .54). Items from factor one captured dependency-oriented dating behaviours that implied women's lack of agency and men's assertiveness and power (e.g., "men should bring gifts for women on a date", "men should highlight their income on a date”, "men should be the ones to initiate contact for a date”). Items from factor two captured gender normative, chivalrous dating behaviours (e.g., "men should offer to pick women up on a date", "men should make sure women get to their cars safely", "men should compliment a women's personality and not her appearance”). Factor one consisting of three items yielded good internal reliability $(\alpha=.70)$ and was used in further analyses as the chivalrous dating beliefs scale. Full list of items and factor analysis can be found on OSF.

\section{Results}

\section{Main Analysis}

Descriptive statistics and zero-order correlations across hostile and benevolent sexism, attachment, self-esteem, and chivalry are presented in Table 1. Consistent with ambivalent sexism theory (Glick \& Fiske, 1996), benevolent and hostile sexism were positively correlated with one another, albeit weakly. Anxious attachment correlated weakly and positively with hostile sexism, but was not significantly correlated with benevolent sexism. This is inconsistent with previous research examining men's attachment styles and endorsement of sexist views which found that men who were relatively more anxiously attached tended to more strongly endorse both benevolent and hostile sexism (Fisher \& Hammond, 2019; Hart et al., 2012). Finally, chivalry correlated weakly and positively with 


\section{Table 1}

Descriptive statistics and zero-order correlations between main variables.

\begin{tabular}{|c|c|c|c|c|c|c|c|c|}
\hline Variable & Mean & SD & 1 & 2 & 3 & 4 & 5 & 6 \\
\hline 1. Benevolent Sexism & 0.42 & 0.96 & - & $.27 * *$ & .16 & -.16 & .01 & $.27 *$ \\
\hline 2. Hostile Sexism & 0.56 & 1.21 & & - & $.34^{* *}$ & .12 & -.20 & $.16^{*}$ \\
\hline 3. Anxious Attachment & 3.78 & 1.24 & & & - & $.36^{* *}$ & $-.54 * *$ & .15 \\
\hline 4. Avoidant Attachment & 3.22 & 1.16 & & & & - & $-.36 * *$ & -.00 \\
\hline 5. Self-Esteem & 4.66 & 1.27 & & & & & - & .10 \\
\hline 6. Chivalry Norms & 2.48 & 1.05 & & & & & & - \\
\hline
\end{tabular}

Note. ${ }^{*} p<.05, * * p<.001$ 
benevolent sexism. Given these two forms of sexism are interrelated, and following prior research, in all of the following analyses on benevolent sexism, I included hostile sexism as a covariate.

An independent samples t-test was conducted as a manipulation check, to test whether the experimental condition (of the word unscrambling task) was successful in activating different states of attachment, manifesting as relatively higher self-esteem for those in the secure condition, and relatively lower self-esteem for those in the anxious condition (Gillath et al., 2006). Participants in the secure condition $(M=4.75, S D=1.25)$ and those in the anxious condition $(M=4.56, S D=1.30)$ did not significantly differ from each other in terms of self-esteem scores, $t(119)=0.82, p=.416, d=0.15$. Thus, the manipulation (word unscrambling task) was unsuccessful in activating different states of attachment.

In order to comprehensively test whether higher need fulfilment (i.e., anxious attachment) causes men who more strongly endorse benevolent sexism to also endorse chivalrous dating behaviours, I conducted a multiple linear regression analysis in Jamovi (2020) to predict men's endorsement of chivalrous dating behaviours from their endorsement of benevolent sexism, experimental condition (secure vs. anxious), and their interaction. Hostile sexism, and the condition-hostile sexism interaction, were included as covariates. Results are shown in Table 2. The results of the multiple regression indicated that the model explained $4.22 \%$ of the variance (adjusted $\mathrm{R}^{2}$ ), and that the overall model was not a significant predictor of endorsement of chivalrous dating behaviours, $F(5,114)=2.05, p=$ .077. Benevolent sexism contributed significantly to the model; however, the experimental condition and interaction term did not. These results indicate that the attachment priming task was not successful in eliciting different responses to the chivalrous dating behaviours scale. As a contingency (see OSF pre-registration for more detail) and to further examine this link, I performed two supplementary analyses to explore whether results would differ when 


\section{Table 2}

Multiple linear regression analysis regressing men's endorsement of chivalrous dating beliefs (Factor 1) by their endorsement of sexist attitudes and experimental condition (secure vs. anxious).

\begin{tabular}{lccccccc}
\hline & & & & & & \multicolumn{2}{c}{$95 \% C I$} \\
\hline \multicolumn{1}{c}{ Predictor Variable } & $B$ & $S E$ & $\beta$ & $t$ & $p$ & Low & High \\
\hline Benevolent Sexism & $\mathbf{0 . 2 7}$ & $\mathbf{0 . 1 0}$ & $\mathbf{0 . 2 4}$ & $\mathbf{2 . 5 8}$ & $\mathbf{. 0 1 1}$ & $\mathbf{0 . 0 6}$ & $\mathbf{0 . 4 7}$ \\
Hostile Sexism & 0.08 & 0.08 & 0.09 & 0.96 & .337 & -0.08 & 0.24 \\
Experimental Condition & -0.03 & 0.19 & -0.03 & -0.18 & .857 & -0.41 & 0.34 \\
BS x Experimental Condition & -0.00 & 0.21 & -0.00 & -0.01 & .992 & -0.41 & 0.41 \\
HS x Experimental Condition & 0.05 & 0.16 & 0.06 & 0.31 & .758 & -0.27 & 0.37
\end{tabular}

Note. Scores for all predictor variables were mean centered. Experimental condition coded as $1=$ secure, and $2=$ anxious. BS $=$ Benevolent Sexism. HS = Hostile Sexism 
(a) when participants' trait attachment was used as a predictor in the model instead of their state attachment (i.e., in place of the experimental prime), and (b) using the alternate factor structure for chivalrous dating beliefs.

\section{Supplementary Analyses}

Given the main analysis was inconclusive due to the failed manipulation task, I conducted a multiple linear regression analysis to predict men's endorsement of chivalrous dating behaviours from their endorsement of benevolent sexism, anxious attachment scores, and their interaction. In addition to hostile sexism being added as a covariate, avoidant attachment scores were also included as a covariate to identify the unique links between anxious attachment and the other variables of interest. The alternate factor structure- - factor 2 - was also used to replicate the two previous multiple linear regressions as an exploratory analysis. I conducted the first multiple regression analysis predicting men's endorsement of chivalrous dating behaviours (factor 2) from their endorsement of benevolent sexism, experimental condition (secure vs. anxious), and their interaction. Then, I conducted the second multiple regression analysis predicting men's endorsement of chivalrous dating behaviours (factor 2) from their endorsement of benevolent sexism, anxious attachment scores, and their interaction. Similar results were found across all three supplementary analyses; benevolent sexism was the only factor which contributed significantly to the model. Data and tables for supplementary analyses can be found on OSF.

\section{Discussion}

The results for Study 1 replicate the benevolent sexism-chivalry link found in Viki et al. (2003) and thus, reveal compelling support for hypothesis H1a. As demonstrated by the correlation between benevolent sexism and chivalry, and the significant main effect of benevolent sexism in all multiple linear regressions that were conducted, the results show strong support for the prediction that men who are more endorsing of benevolent sexism are 
also more endorsing of chivalrous dating behaviours (H1a). The failed manipulation check suggests that the procedure used for eliciting feelings of relational security vs. relational insecurity may be flawed. As such, support for hypotheses H1b and H1c are inconclusive. Thus, there is neither support or lack of support that men who more strongly endorse benevolent sexism and are more anxiously attached tend to also be more endorsing of chivalrous dating behaviours (H1b). Furthermore, we cannot conclude from these results whether anxious attachment causes men who are more endorsing of benevolent sexism to also be more endorsing of chivalrous dating behaviours (H1c).

Study 1 did present limitations which will need to be addressed going forward with Study 2. First, the failed attachment priming manipulation suggests that the items devised for the word unscrambling task were not effective enough to elicit feelings of relational security or insecurity in participants. Thus, we conducted the manipulation task again in Study 2 to test whether this method is replicable. The unmet prediction that anxious attachment causes men who are more strongly endorsing of benevolent sexism to more strongly endorse chivalrous dating behaviours also indicates the possibility of an alternative mechanism at play. Therefore, we tested both attachment orientations and men's psychological entitlement as potential moderators of the link between men's endorsement of benevolent sexism and their endorsement of chivalrous dating behaviours.

\section{Study 2}

Study 2 aimed to replicate Study 1 by testing whether men who more strongly endorse benevolent sexism also tend to strongly endorse chivalrous dating behaviours (H1a), whether this association is heightened when men are more anxiously attached (H1b), and whether priming an anxious attachment causes stronger endorsement of chivalrous dating behaviours (H1c). Study 2 was also conducted online and experimentally manipulated attachment orientations using a word priming task. Modifications to methods were also 
changed. First, I included more items from the original measure of paternalistic chivalry by Viki et al. (2003) to improve the coherence of the chivalrous behaviours factor. Second, I used a more direct replication of the word unscrambling task used in Finkel et al. (2007) for the attachment prime (albeit still including measures required for the current study). Third as I attempted to replicate the above findings, I increased statistical power to 100 participants per group (i.e., $N=200$ ), sufficient to detect a low-to-medium effect size of $d=0.4$ (Cohen, 1988) with $80 \%$ power in an independent samples t-test. However, to account for potential deletion of non-compliant responses, participants who do not wish for their data to be used for research, an/or participants who are aware of the measures or manipulation (e.g., indicate having completed the word unscrambling task in a prior study), I aimed to recruit 240 participants for Study 2.

Study 2 also added measures of grandiose narcissism and vulnerable narcissism as potential alternative moderators. Men who more strongly endorse benevolent sexism may not necessarily engage or endorse chivalrous dating behaviours as a means to fulfil relational needs, but rather because they feel a sense of entitlement (Hammond et al., 2013), to preserve and/or demonstrate power over women by rendering them dependent through such acts (Hyun et al., 2016; Leone et al., 2020). For example, it has been shown that individuals high on trait narcissism give gifts within romantic relationships as a means to maintain reciprocity (Hyun et al., 2016). Furthermore, preoccupations with maintaining power and high-status by behaving chivalrously are uniquely male tendencies, as gender norms dictate that men should have the resources and abilities to provide for and protect others, particularly women-a phenomenon termed the 'white knight effect' (Leone et al., 2020). Therefore, benevolently sexist men may tend to endorse chivalrous dating behaviours primarily to enhance their perceived social status/self-presentation (i.e., grandiose narcissism) and alleviate concerns 
over maintaining their masculinity (i.e., vulnerable narcissism), rather than to fulfil relational needs and alleviate general relationship insecurities.

\section{Method}

\section{Participants}

Similar to Study 1, participants were recruited through Prolific, the online participant recruitment website. Two hundred and forty six participants completed the study which was hosted on Qualtrics. Five participants were excluded as they did not identify as being heterosexual (four identifying as bisexual and one as asexual), three were excluded for exhibiting a response bias, and 15 had specified that they had completed the word unscrambling task before. From the remaining participants $(N=223), 199$ identified as single, eight were casually dating, nine were in a serious relationship, five were living together with a partner, and two were married. All participants identified as heterosexual males. Participants were on average 34.4 years old $(S D=12.4)$.

\section{Materials}

Participants completed the same measures examining endorsement of hostile $(\alpha=$ .89). and benevolent sexism $(\alpha=.79)$, and attachment orientation $(\alpha=.83)$ as in Study 1 . Participants also completed the same measure of self-esteem for the purposes of a manipulation check $(\alpha=.93)$.

\section{Manipulation of Attachment Orientation}

Similar to Study 1, participants completed a priming task that required them to unscramble sentences to manipulate their attachment orientation. The word unscrambling task used in Study 2 was adopted from Finkel et al. (2007), using the exact wording and presentation of items. This procedure also required participants to omit the 'odd word out' to form a complete and meaningful sentence with the remaining words. For example, "she, door, walked, the, painted" would be unscrambled to create the sentence "she painted the 
door", omitting the word "walked". Two sets of sentences were used; one priming attachment anxiety (e.g., "the child felt vulnerable) and one priming attachment security (e.g., "the child felt protected). Both lists consisted of seven scrambled sentences and three neutral filler sentences. All items can be found in supplementary materials on OSF.

\section{Endorsement of Paternalistic Chivalry}

Participants also completed the 10-item measure of paternalistic chivalry (Viki et al., 2003) to examine their endorsement of chivalrous dating behaviours (e.g., "It is up to the man to decide where the couple are to have their dinner date"; $1=$ Strongly Disagree, $7=$ Strongly Agree). Higher scores indicated greater endorsement of chivalrous dating behaviours. Eleven items from the devised chivalry scale in Study 1 that were distinct from Viki et al.'s (2003) measure of paternalistic chivalry were also included in the questionnaire for the purposes of an exploratory factor analysis.

To explore the factor structure of this second chivalrous dating behaviour scale (which will henceforth be referred to as the 'paternalistic chivalry scale' to avoid confusion), the 21 items along with the 11 benevolent sexism items from the Ambivalent Sexism Inventory (Glick \& Fiske, 1996) were subjected to an exploratory factor analysis in Jamovi (2020). A principal axis factoring extraction method was used in combination with an oblique (promax) rotation. This method was adopted to extract items that did not have high loadings (values > .30) on the existing benevolent sexism subscale (see Viki et al., 2003). Factors were extracted with the criterion of eigenvalues larger than one (Kaiser, 1960).

Similar to results from Study 1, the exploratory factor analysis yielded a three factor solution being the best fit for the data, one being the existing benevolent sexism subscale. Six items loaded highly onto the benevolent sexism subscale (ranging from .35 to .52 ). Factor one consisted of 11 items pertaining to dependency-oriented dating behaviours that also appeared to be chivalrous in nature. Ten items were from Viki et al.'s (2003) paternalistic 
chivalry scale including one additional item ("men should be the first to call/text after a date"). Factor two consisted of three items and pertained to behaviours that showed off men's resources (e.g., “men should talk about how much they earn on a first date”). The two factors were subjected to a reliability analysis. Factor one displayed very good internal reliability $(\alpha=.91)$ as well as factor two (three items; $\alpha=.81)$. Thus, factor one, was used in further analyses for Study 2 as the paternalistic chivalry scale. Analyses and items can be found on OSF.

\section{Grandiose Narcissism}

Participants' concerns over maintaining social standing and enhancing selfpresentation was measured using the Narcissistic Personality Inventory-13 (NPI-13; Gentile et al., 2013). Thirteen items assessed grandiose narcissism, which each item presenting two options (a pair of contrasting attributes) (e.g., "I find it easy to manipulate people" vs. "I don't like it when I find myself manipulating people”). Participants chose the option that they most agreed with for each of the 13 items. Higher scores indicated greater grandiose narcissism. The scale displayed acceptable internal reliability $(\alpha=.68)$.

\section{Vulnerable Narcissism}

Participants' concerns over their masculinity was assessed using the Hypersensitive Narcissism Scale (Hendin \& Cheek, 1997). Ten items measured vulnerable narcissism (e.g., "My feelings are easily hurt by ridicule or the slighting remarks of others"; 1 = Strongly Disagree, 7 = Strongly Agree) with higher scores indicating greater vulnerable narcissism. The scale displayed good reliability overall $(\alpha=.77)$.

\section{Procedure}

Participants were screened based on eligibility criteria (heterosexual, male) through Prolific. Eligible participants then gained access to the questionnaire via Qualtrics and were presented with an information page. Participants then proceeded to the consent page and were 
made aware that they could exit the survey at any time, skip questions, and retract their responses at the end of the survey. Participants gave consent by agreeing to the terms and continuing with the study, and were required to complete the study in one sitting (approximately one hour).

Participants were presented with the same demographic questions as in Study 1, along with the Ambivalent Sexism Inventory, and Adult Attachment Questionnaire. Participants were once again randomly assigned to be in either the secure or anxious condition for the word unscrambling task. Approximately half of participants complete the secure version of the task $(N=112)$, while the other half completed the anxious version $(N=111)$. Participants were then presented with an array of questionnaires including the Rosenberg Self-Esteem Scale, Paternalistic Chivalry scale, NPI-13, and Hypersensitive Narcissism Scale. After completing all questionnaires, participants were debriefed and given $£ 1(\mathrm{GBP})$ for participating in the study.

\section{Results}

\section{Main Analysis}

Descriptive statistics and zero-order correlations across hostile and benevolent sexism, attachment, self-esteem, paternalistic chivalry, and narcissism (grandiose and vulnerable) are presented in Table 3. Unsurprisingly, benevolent and hostile sexism were positively correlated with one another. Although this was a weak correlation it is consistent with ambivalent sexism theory (Glick \& Fiske, 1996). Also consistent with the findings of Fisher and Hammond (2019), and Hart et al. (2012), anxious attachment was weakly and positively correlated with both benevolent and hostile sexism. Paternalistic chivalry was weakly and positively correlated with both benevolent and hostile sexism. Both grandiose and vulnerable narcissism did not significantly correlate with paternalistic chivalry, and while grandiose narcissism positively correlated with benevolent and hostile sexism, vulnerable 


\section{Table 3}

Descriptive statistics and zero-order correlations between main variables.

\begin{tabular}{|c|c|c|c|c|c|c|c|c|c|c|}
\hline Variable & Mean & $\mathrm{SD}$ & 1 & 2 & 3 & 4 & 5 & 6 & 7 & 8 \\
\hline 1. Benevolent Sexism & 0.36 & 0.87 & - & $.20 *$ & $.17 *$ & $-.20 *$ & .03 & $.40 * *$ & $.21 *$ & .10 \\
\hline 2. Hostile Sexism & 0.37 & 1.08 & & - & $.22 *$ & $.30 * *$ & $-.16^{*}$ & $.36^{* *}$ & $.23 * *$ & $.35^{* *}$ \\
\hline 3. Anxious Attachment & 3.76 & 0.93 & & & - & $.23 * *$ & $-.44 * *$ & .11 & .03 & $.47 * *$ \\
\hline 4. Avoidant Attachment & 3.70 & 1.15 & & & & - & $-.35 * *$ & .12 & .03 & $.45^{* *}$ \\
\hline 5. Self-Esteem & 4.25 & 1.28 & & & & & - & .03 & .09 & $-.51 * *$ \\
\hline 6. Paternalistic Chivalry & 2.42 & 1.00 & & & & & & - & .09 & .11 \\
\hline 7. Grandiose Narcissism & 0.19 & 0.18 & & & & & & & - & .10 \\
\hline 8. Vulnerable Narcissism & 4.01 & 0.89 & & & & & & & & - \\
\hline
\end{tabular}

Note. ${ }^{*} p<.05, * * p<.001$ 
narcissism was only positively correlated with hostile sexism. This is inconsistent with supplementary predictions that scoring relatively high on both types of narcissism would be related to greater endorsement of benevolent sexism and paternalistic chivalry for the purposes of maintaining social standing (i.e., grandiose narcissism) and reinforcing masculinity (i.e., vulnerable narcissism).

Similar to Study 1, an independent samples t-test was conducted as a manipulation check, to test whether the experimental condition (of the word unscrambling task) was successful in activating different states of attachment. Participants in the secure condition $(M$ $=4.30, S D=1.26)$ and those in the anxious condition $(M=4.20, S D=1.30)$ did not significantly differ from each other in terms of self-esteem scores, $t(221)=0.57, p=.571, d=$ 0.08. Thus, the manipulation (word unscrambling task) was unsuccessful in activating different states of attachment.

To test hypothesis H1c — whether higher need fulfilment (i.e., anxious attachment) causes men who more strongly endorse benevolent sexism to also endorse paternalistic chivalry-I conducted a multiple linear regression analysis in Jamovi (2020) to predict men's endorsement of paternalistic chivalry from their endorsement of benevolent sexism, experimental condition (secure vs. anxious), and their interaction. Hostile sexism was included as a covariate to identify the unique links between benevolent sexism and the other variables of interest. Results are shown in Table 4 . The results of the multiple regression indicated that the model explained $25.10 \%$ of the variance (adjusted $\mathrm{R}^{2}$ ), and that the overall model was a significant predictor of endorsement of paternalistic chivalry, $F(5,216)=15.8$, $p<.001$. Benevolent sexism contributed significantly to the model. However, the experimental condition and interaction term did not. Interestingly, hostile sexism and the interaction between hostile sexism and experimental condition was significant. To further 


\section{Table 4}

Multiple linear regression analysis regressing men's endorsement of paternalistic chivalry by their endorsement of sexist attitudes and experimental condition (secure vs. anxious).

\begin{tabular}{lccccccc}
\hline & & & & & & \multicolumn{2}{c}{$95 \% C I$} \\
\hline \multicolumn{1}{c}{ Predictor Variable } & $B$ & $S E$ & $\beta$ & $t$ & $p$ & Low & High \\
\hline Benevolent Sexism & $\mathbf{0 . 4 1}$ & $\mathbf{0 . 0 7}$ & $\mathbf{0 . 4 4}$ & $\mathbf{5 . 9 3}$ & $<.001$ & $\mathbf{0 . 2 7}$ & $\mathbf{0 . 5 4}$ \\
Hostile Sexism & $\mathbf{0 . 2 7}$ & $\mathbf{0 . 0 6}$ & $\mathbf{- 0 . 1 0}$ & $\mathbf{4 . 8 9}$ & $<.001$ & $\mathbf{0 . 1 5}$ & $\mathbf{0 . 3 8}$ \\
Experimental Condition & -0.15 & 0.12 & -0.01 & -1.27 & .205 & -0.38 & 0.08 \\
BS x Experimental Condition & -0.13 & 0.14 & -0.16 & -0.97 & .334 & -0.41 & 0.14 \\
HS x Experimental Condition & $\mathbf{0 . 2 9}$ & $\mathbf{0 . 1 1}$ & $\mathbf{- 0 . 1 5}$ & $\mathbf{2 . 6 3}$ & $\mathbf{. 0 0 9}$ & $\mathbf{0 . 0 7}$ & $\mathbf{0 . 5 1}$
\end{tabular}

Note. Scores for all predictor variables were mean centered. Experimental condition coded as $1=$ secure, and $2=$ anxious. BS $=$ Benevolent Sexism. HS $=$ Hostile Sexism. 
explore this interaction a simple slopes analysis was conducted with the simple slopes function in Jamovi (2020).

The simple slope for participants in the secure condition was non-significant $(B=$ $0.12, S E=0.08, t=1.65, p=.101)$. However, the simple slope for participants in the anxious condition was significant $(B=0.41, S E=0.08, t=5.16, p<.001)$. As depicted in Figure 2, the simple slopes analysis indicated that for men who were primed to be more anxiously attached, their endorsement of paternalistic chivalry was greater when they also more strongly endorsed hostile sexism. For men who were primed to be more securely attached, their endorsement of paternalistic chivalry did not differ depending upon their endorsement of hostile sexism.

\section{Figure 2}

\section{Simple slopes analysis of the interaction between men's endorsement of hostile sexism and}

\section{experimental condition}

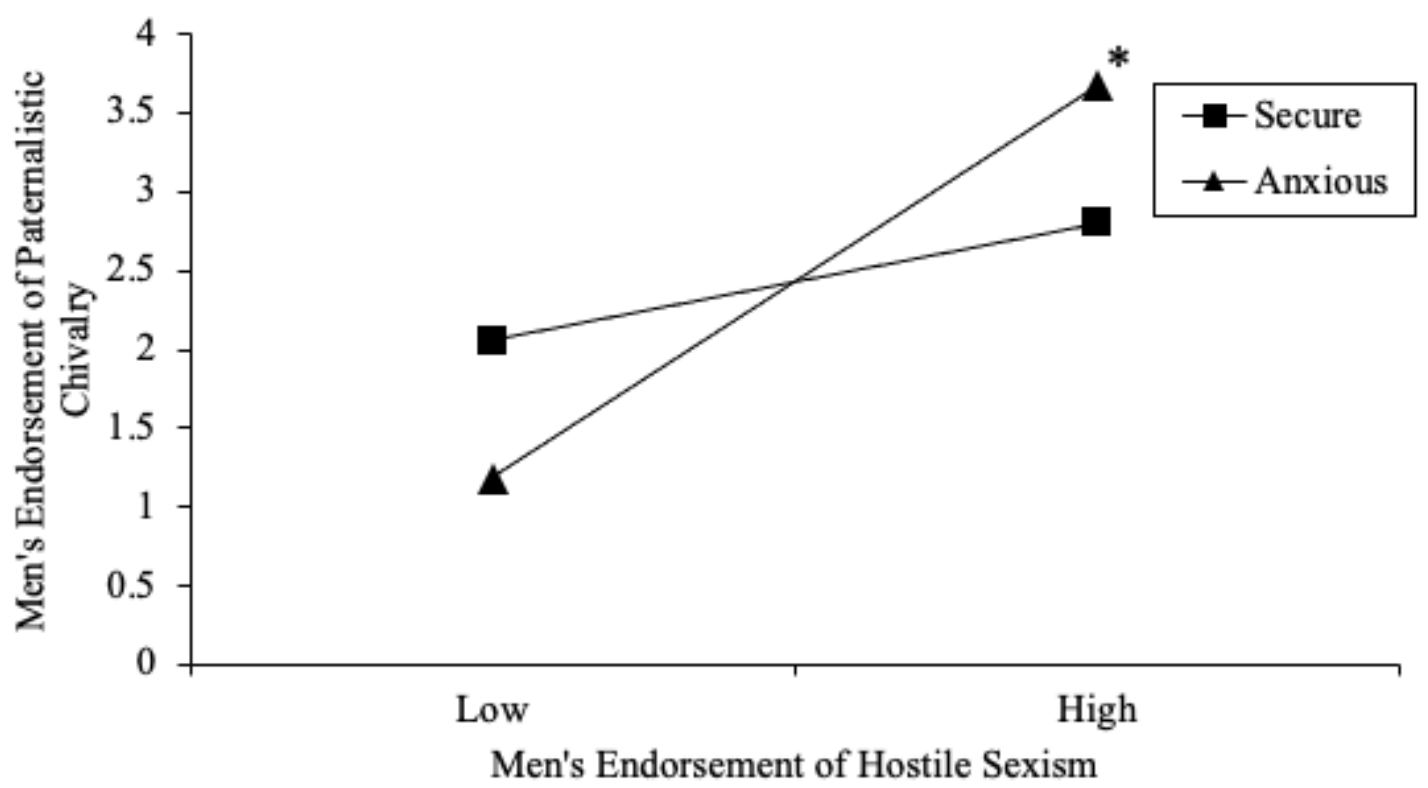

Note. ${ }^{*} \mathrm{p}<.001$ 
Consistent with results from Study 1, these findings indicate that the attachment priming task did not successfully moderate the link between benevolent sexism and paternalistic chivalry. I performed additional analyses similar to Study 1, examining participants' trait attachment as a predictor instead of their state attachment (i.e., the experimental condition). To explore whether grandiose and vulnerable narcissism are potential moderators between the benevolent sexism-paternalistic chivalry link, I also conducted a second supplementary analysis to test this alternate hypothesis.

\section{Supplementary Analysis}

To explore whether participants' trait attachment moderates the link between men's endorsement of benevolent sexism and paternalistic chivalry, I conducted a multiple linear regression to predicts men's endorsement of dating behaviours from their endorsement of benevolent sexism, and anxious attachment scores, and their interaction. In line with standard procedures, both hostile sexism and avoidant attachment scores were included as covariates to examine unique links between benevolent sexism, anxious attachment, and paternalistic chivalry. Results are shown in Table 5. The results of the multiple regression indicated that the model explained $24.70 \%$ of the variance (adjusted $\mathrm{R}^{2}$ ), and that the overall model was a significant predictor of endorsement of paternalistic chivalry, $F(8,213)=10.00, p<.001$. Benevolent sexism contributed significantly to the model. However, anxious attachment and the interaction between benevolent sexism and anxious attachment did not. Interestingly, hostile sexism and avoidant attachment also contributed significantly to the model.

I also conducted another supplementary analysis that examines the potential moderating role of grandiose and vulnerable narcissism. A multiple linear regression was used to predict men's endorsement of paternalistic chivalry from their endorsement of benevolent sexism, grandiose narcissism scores, vulnerable narcissism scores, and their interaction terms (with hostile sexism included as a covariate). Results are shown in Table 6. 


\section{Table 5}

Multiple linear regression analysis regressing men's endorsement of paternalistic chivalry by their endorsement of sexist attitudes and trait attachment style.

\begin{tabular}{|c|c|c|c|c|c|c|c|}
\hline & & & & & & \multicolumn{2}{|c|}{$95 \% C I$} \\
\hline Predictor Variable & $B$ & $S E$ & $\beta$ & $t$ & $p$ & Low & High \\
\hline Benevolent Sexism & 0.38 & 0.08 & 0.33 & 4.79 & $<.001$ & 0.22 & 0.53 \\
\hline Hostile Sexism & 0.30 & 0.07 & 0.32 & 4.55 & $<.001$ & 0.17 & 0.43 \\
\hline Anxious Attachment & -0.06 & 0.07 & -0.05 & -0.81 & .416 & -0.19 & 0.08 \\
\hline Avoidant Attachment & 0.12 & 0.06 & 0.13 & 1.99 & .048 & 0.00 & 0.23 \\
\hline BS x Anxious Attachment & 0.07 & 0.07 & 0.06 & 1.02 & .311 & -0.07 & 0.21 \\
\hline BS x Avoidant Attachment & 0.09 & 0.05 & 0.09 & 1.62 & .107 & -0.02 & 0.19 \\
\hline HS x Anxious Attachment & -0.05 & 0.07 & -0.05 & -0.80 & .422 & -0.18 & 0.08 \\
\hline HS x Avoidant Attachment & -0.07 & 0.05 & -0.09 & -1.44 & .152 & -0.16 & 0.03 \\
\hline
\end{tabular}

Note. Scores for all predictor variables were mean centered. BS = Benevolent Sexism. HS = Hostile Sexism. 


\section{Table 6}

Multiple linear regression analysis regressing men's endorsement of paternalistic chivalry by their endorsement of sexist attitudes, grandiose narcissism, and vulnerable narcissism.

\begin{tabular}{lccccccc}
\hline & & & & & & \multicolumn{2}{c}{$95 \%$ CI } \\
\hline \multicolumn{1}{c}{ Predictor Variable } & $B$ & $S E$ & $\beta$ & $t$ & $p$ & Low & High \\
\hline Benevolent Sexism & $\mathbf{0 . 3 8}$ & $\mathbf{0 . 0 7}$ & $\mathbf{0 . 3 3}$ & $\mathbf{5 . 1 5}$ & $<.001$ & $\mathbf{0 . 2 4}$ & $\mathbf{0 . 5 3}$ \\
Hostile Sexism & $\mathbf{0 . 3 2}$ & $\mathbf{0 . 0 6}$ & $\mathbf{0 . 3 4}$ & $\mathbf{4 . 8 9}$ & $<.001$ & $\mathbf{0 . 1 9}$ & $\mathbf{0 . 4 4}$ \\
Grandiose Narcissism & -0.27 & 0.37 & -0.05 & -0.74 & .458 & -0.99 & 0.45 \\
Vulnerable Narcissism & -0.02 & 0.07 & -0.02 & -0.34 & .731 & -0.17 & 0.12 \\
BS x Grandiose Narcissism & -0.65 & 0.40 & -0.10 & -1.62 & .107 & -1.44 & 0.14 \\
BS x Vulnerable Narcissism & 0.08 & 0.07 & 0.06 & 1.16 & .247 & -0.06 & 0.22 \\
HS x Grandiose Narcissism & 0.12 & 0.38 & 0.02 & 0.32 & .747 & -0.62 & 0.87 \\
HS x Vulnerable Narcissism & -0.04 & 0.05 & -0.04 & -0.77 & .440 & -0.15 & 0.06
\end{tabular}

Note. Scores for all predictor variables were mean centered. BS = Benevolent Sexism. HS = Hostile Sexism. 
The results of the multiple regression indicated that the model explained $22.40 \%$ of the variance (adjusted $\mathrm{R}^{2}$ ), and that the overall model was a significant predictor of endorsement of paternalistic chivalry, $F(8,210)=8.86, p<.001$. Benevolent sexism contributed significantly to the model, as did hostile sexism. Grandiose narcissism and vulnerable narcissism did not contribute significantly to the model; neither did the interaction between benevolent sexism and grandiose narcissism, and benevolent sexism and vulnerable narcissism.

\section{Discussion}

These findings offer strong support for hypothesis H1a. Replicating similar results as Study 1, benevolent sexism correlated significantly with paternalistic chivalry, and was a significant predictor of paternalistic chivalry in all multiple linear regressions that were ran. Thus, it is clear that there is a positive association between endorsing benevolent sexism and endorsing paternalistic chivalry, in line with previous research demonstrating that men who are more endorsing of benevolent sexism tend to also be more endorsing of such dependencyoriented dating behaviours (Viki et al., 2003). Also similar to Study 1 results, the manipulation failed to prime attachment anxiety and attachment security. Thus, it cannot be concluded whether or not there was support for hypotheses H1b (that men who are more endorsing of benevolent sexism and are more anxiously attached tend to also be more endorsing of paternalistic chivalry), and $\mathrm{H} 1 \mathrm{c}$ (that anxious attachment causes men who more strongly endorse benevolent sexism to be more endorsing of paternalistic chivalry).

In regards to the supplementary predictions that grandiose and vulnerable narcissism moderate the association between men's endorsement of benevolent sexism and paternalistic chivalry, the results suggest that grandiose and vulnerable narcissism do not play a moderating role. The findings also suggest that the endorsement of paternalistic chivalry is not predicted by (or is associated with) grandiose and vulnerable narcissism. This is 
inconsistent with existing research that link chivalrous and romantic gestures (e.g., gift giving and bystander intervention at parties) with motivations to maintain high power and status (i.e., grandiose narcissism; Hyun et al., 2016), and motivations to uphold masculinity norms (i.e., vulnerable narcissism; Leone et al., 2020).

Somewhat in line with previous research, grandiose narcissism correlated positively with benevolent and hostile sexism, but vulnerable narcissism did not significantly correlate with either. Benevolent sexism encompasses the belief that men should provide for and protect women, thereby rendering women dependent upon men and granting men a sense of power. Grandiose narcissism, concerned with maintaining high status and power, should thus, be linked to the endorsement of benevolent sexism. As both grandiose narcissism and hostile sexism are concerned with men's dominance in the wider social sphere, it is not surprising that the two are also positively correlated. Vulnerable anxiety on the other hand, did not correlate with benevolent sexism despite Leone et al.'s (2020) findings that concerns over adherence to masculine norms was positively associated with endorsement of benevolent sexism. Thus, the motivation to enhance perceived social status and power may be more strongly linked to men's greater endorsement of benevolent sexism, compared to men's motivation to adhere to masculine norms. However, this motivation is not enough for men (who more strongly endorse benevolent sexism) to endorse chivalrous dating behaviours, as the two supplementary predictors were not found to be significant predictors of paternalistic chivalry, nor did they yield any significant interactions with benevolent sexism.

Study 2 found a positive correlation between hostile sexism and paternalistic chivalry which was also found in Study 1. Surprisingly, results from Study 2 (but not Study 1) indicated that hostile sexism was a consistent and significant predictor of paternalistic chivalry in all analyses that were conducted. A significant interaction effect between hostile sexism and the priming condition was also found in the first regression analyses of Study 2. 
That is, men who more strongly endorsed hostile sexism and were primed to be anxiously attached tended to more strongly endorse paternalistic chivalry. These novel findings point to hostile sexism playing a larger role than benevolent sexism when examining chivalrous dating behaviours and dependency-oriented support behaviours in general. To examine whether this pattern of findings will hold in a more ecologically valid scenario, Study 3 was conducted.

\section{Study 3}

In this last study, I aim to test the model proposed in Figure 1. This study will replicate the previous two studies which examined the pathway between men's endorsement of benevolent sexism and dependency-oriented support (provision), as well as examining the pathway between women's endorsement of benevolent sexism and dependency-oriented support (acceptance). It is predicted that men who more strongly endorse benevolent sexism will tend to provide more dependency-oriented support (H1a), and this association will be stronger when men are relatively more anxiously attached (H1b). Similarly, it is predicted that women who more strongly endorse benevolent sexism will tend to be more accepting of dependency-oriented support $(\mathrm{H} 2 \mathrm{a})$, and this association will be stronger when women are relatively more anxiously attached $(\mathrm{H} 2 \mathrm{~b})$. This study will also test hypothesis $\mathrm{H} 3$, which explores whether men's provision of dependency-oriented support and women's acceptance of dependency-oriented support fulfils core relational needs - a prediction informed by both ambivalent sexism and attachment theory which has yet to be tested.

Study 3 extends upon Study 1 and 2 by not only testing the entirety of the model, but also by investigating dependency-oriented support during couples' discussions of their personal goals with one another. This methodology is stronger in ecological validity as it (a) examines couples interactions with one another in real time (compared with examining participants endorsement of hypothetical behaviours online), and (b) examines how support 
provision and acceptance may manifest in real life (i.e., through goal discussion). This paradigm has been used in a previous study by Hammond and Overall (2015) examining support behaviours within relationships. Specifically, the discussions elicit support behaviours which can either be autonomy-oriented (e.g., encouraging partners to pursue their own goals), or dependency-oriented (e.g., providing partners with direct advice and dominating the discussion). The discussions allow both partners to be in the role of the support provider and support recipient.

\section{Method}

\section{Participants}

Participants were recruited through email and physical advertisements posted across a New Zealand University campus (Victoria University of Wellington). One hundred and fifty three couples participated in the study, with 50\% stating they were either living together or married. Couples in the sample have been together on average for 3.28 years $(S D=4.13$ years). The female participants were on average 21.97 years old $(S D=5.65)$ and males on average $23.31(S D=7.24)$ years old. Seventy nine heterosexual couples' discussions were coded and made up the final sample $(N=158)$.

\section{Materials}

Participants completed the same measures examining endorsement of hostile $(\alpha=.92)$ and benevolent sexism $(\alpha=.83)$, and attachment orientations $(\alpha=.82)$ as in Study 1 and Study 2.

\section{Satisfaction of Relational Needs}

Participants' completed three items from the Perceived Partner Responsiveness Scale (Reis \& Carmichael, 2006) which assessed for how satisfied they felt after the interaction with their partner, in terms of their needs (e.g., "In that interaction I felt loved and cared 
for"; 1 = Not at all, 7 = Very). Higher scores indicate greater satisfaction/fulfilment of relational needs. The scale displayed good internal reliability $(\alpha=.89)$.

\section{Procedure}

Participants who were eligible to participate in the study were required to come into the lab with their current romantic partner. Participants were given general information about the study and procedures, and researchers obtained their consent to be video and audio recorded during a discussion of personal goals. First, participants engaged in a communication game where one partner was randomly chosen to give instructions, and the other partner was to receive the instructions. Participants completed two variations of the communication game, so that each partner had a turn at being the one giving instructions in one task and receiving instructions in the other.

After the communication games, participants each identified four personal goals relating to their education/career, health, relationship, and personal interests, that participants would hold for at least the next nine months. Participants also completed measures of demographics, sexist attitudes, and attachment orientation separately. Participants then took turns (order counterbalanced for gender) discussing one personal goal (randomly chosen by the experimenter) with their partner. Each partner had a turn at being the one providing support in one interaction (i.e., when discussing their partner's personal goal) and receiving support in the other interaction (i.e., when discussing their own personal goal). After each interaction participants completed the relational needs measures which assessed for how satisfied participants felt during the interaction they had with their partner. Participants were given the choice of either a $\$ 10$ (NZD) fuel or grocery voucher for participating in the study and were debriefed about more specific study aims after completion.

\section{Coding Procedure}


To examine support behaviours during couples' goal discussions, three trained coders rated participants' provision of dependency-oriented support when in the role of the support provider, and whether participants accepted or objected their partners' support attempts when in the role of the support recipient. The coding scheme for support provision was adopted from a previous study investigating support provision in goal-related discussions (Hammond \& Overall, 2015), and the coding scheme for support acceptance/objection was adapted from Overall et al.'s (2011) study investigating influence tactics during conflict discussions (Overall et al., 2011). Six support provision behaviours (autonomy facilitating, autonomy impeding, competence facilitating, competence impeding, relatedness facilitating, relatedness impeding; Ryan \& Deci, 2000) and two support receiving behaviours (acceptance, objection) were coded. Coders rated the degree to which each support type and support response was exhibited during discussions on a 7-point scale $(1=$ low, $7=$ high $)$, taking into consideration the frequency, intensity, and duration of each behaviour and/or response.

Dependency-oriented support was conceptualised as a type of support behaviour that impedes the recipient's fulfilment of their autonomy and the lack of competence facilitating behaviours (Hammond \& Overall, 2015). The impediment of autonomy needs (concerned with supporting a partner's independence in achieving his/her own goal) and the lack of facilitating competence needs (concerned with reinforcing a partner's capabilities in achieving his/her own goal) are central to dependency-oriented support as it involves directly assisting others in a domineering manner rather than enabling others' to independently pursue their own goals. Dependency-oriented support consisted of behaviours such as dominating/frequently interjecting during the conversation, communicating direct solutions, and neglecting the recipient's skills or abilities (Hammond \& Overall, 2015).

Acceptance of partners' support provision was conceptualised as an openness to the support provider's influence (see Overall et al., 2011). Being open to influence is a response 
that communicates the recipient acknowledges and understands the support providers viewpoints and attempts at offering the recipient support. Acceptance consisted of behaviours such as showing openness and agreement with the support provider's opinions, and verbal or behavioural expression of positive affect towards the support provider during their support attempts (Overall et al., 2011).

Objection of partners' support provision was conceptualised as being closed to the support provider's influence (see Overall et al., 2011). Being closed to influence is a response that communicates the recipient disagrees or is invalidating the support providers viewpoints and attempts at offering the recipient support. Objection consisted of behaviours such as derogating and disagreeing the support provider's opinions, demanding changes from the support provider, and verbally or behaviourally adopting a domineering, non-negotiating stance when their partner is offering support (Overall et al., 2011).

\section{Results}

\section{Inter-Rater Reliability}

Intra class correlation analyses were performed on the 79 observations in SPSS (2020). A two-way random effect model based on single ratings and absolute agreement assessed inter-rater reliability. Intra class correlations for all coded variables and $95 \%$ confidence intervals are displayed in Table 7. A high degree of reliability was found between coders' scores for all six support provision variables, as well as acceptance and objection.

\section{Main Analyses}

Descriptives and zero order correlations across the main study variables are presented in Table 8 and split by gender. For both men and women, benevolent and hostile sexism were correlated moderately and positively in line with ambivalent sexism theory (Glick \& Fiske, 1996). Anxious attachment correlated positively with benevolent and hostile sexism for men, consistent with Fisher and Hammond (2019) and Hart et al. (2012). However, anxious 
attachment was not correlated with either forms of sexism for women. Dependency-oriented support provision was positively correlated with hostile sexism but not benevolent sexism for men. This is inconsistent with previous research findings, and the current study theorising that men who are more endorsing of benevolent sexism also provide partners with more dependency-oriented support (Hammond \& Overall, 2015; Shnabel et al., 2016).

Surprisingly, women's endorsement of benevolent sexism correlated positively with dependency-oriented support and anxious attachment, although the latter finding was marginally significant. Need fulfilment was not correlated with dependency-oriented support provision for both men and women, but correlated negatively with women's attachment avoidance. Women's endorsement of benevolent sexism correlated negatively with their acceptance of support; however, to test the direction of this relationship, multiple linear regressions were computed.

\section{Table 7}

Intra-class correlations of coded variables

$95 \% C I$

\begin{tabular}{lcccccc}
\multicolumn{1}{c}{ Variable } & ICC & Low & High & & F & p \\
& & & & & \\
\hline Autonomy Facilitating & .70 & 0.59 & 0.79 & 6.30 & $<.001$ \\
Autonomy Impeding & .88 & 0.82 & 0.92 & 17.89 & $<.001$ \\
Competence Facilitating & .86 & 0.80 & 0.90 & 14.74 & $<.001$ \\
Competence Impeding & .79 & 0.70 & 0.85 & 11.64 & $<.001$ \\
Relatedness Facilitating & .84 & 0.77 & 0.89 & 12.17 & $<.001$ \\
Relatedness Impeding & .82 & 0.75 & 0.88 & 10.76 & $<.001$ \\
Acceptance & .83 & 0.75 & 0.88 & 10.84 & $<.001$ \\
Objection & .92 & 0.88 & 0.94 & 25.25 & $<.001$ \\
& & & & & & \\
\end{tabular}




\section{Table 8}

Descriptive statistics and zero-order correlations between main variables.

\begin{tabular}{|c|c|c|c|c|c|c|c|c|c|c|c|}
\hline \multicolumn{3}{|c|}{ Men } & \multicolumn{2}{|c|}{ Women } & \multirow[b]{2}{*}{1} & \multirow[b]{2}{*}{2} & \multirow[b]{2}{*}{3} & \multirow[b]{2}{*}{4} & \multirow[b]{2}{*}{5} & \multirow[b]{2}{*}{6} & \multirow[b]{2}{*}{7} \\
\hline Variable & Mean & SD & Mean & SD & & & & & & & \\
\hline 1. Benevolent Sexism & 0.52 & 1.11 & 1.18 & 0.96 & - & $.46 * *$ & $.29 *$ & -.02 & .16 & -.01 & -.01 \\
\hline 2. Hostile Sexism & 1.10 & 1.25 & 1.49 & 1.22 & $.46 * *$ & - & $.25^{*}$ & $.23^{*}$ & $.25^{*}$ & $-.22 \dagger$ & $-.22 \dagger$ \\
\hline 3. Anxious Attachment & 2.85 & 1.07 & 3.22 & 1.11 & -.00 & .20 & - & $.22 *$ & -.01 & -.11 & -.13 \\
\hline 4. Avoidant Attachment & 2.67 & 0.86 & 2.94 & 0.95 & -.01 & -.04 & $.28^{*}$ & - & -.18 & -.19 & -.06 \\
\hline 5. D/Oriented Support & 3.53 & 1.10 & 3.41 & 0.98 & $.30 *$ & .18 & $.22 \dagger$ & .06 & - & .00 & $-.26^{*}$ \\
\hline 6. Need Fulfilment & 3.83 & 0.40 & 3.76 & 0.38 & -.17 & -.03 & -.14 & $-.37 * *$ & -.12 & - & $.25^{*}$ \\
\hline 7. Acceptance & 3.36 & 1.17 & 3.72 & 1.31 & $-.25^{*}$ & $-.24 *$ & -.13 & -.07 & $-.35^{*}$ & $.22 \dagger$ & - \\
\hline
\end{tabular}

Note. Correlations for men above the diagonal, correlations for women below the diagonal.

${ }^{*} p<.05,{ }^{* *} p<.001, \dagger$ marginally significant at the $p=.05$ level. 
I conducted the first multiple linear regression to test the hypothesis that men who more strongly endorse benevolent sexism should provide more dependency-oriented support (H1a), and that this association is heightened when men are also relatively more anxiously attached (H1b). As observations are dyadic and thus, non-independent, I used the MIXED procedure in SPSS (Kenny, 1996; Wickham \& Knee, 2012) to regress dependency-oriented support provision on gender, benevolent sexism, and anxious attachment. Hostile sexism and avoidant attachment were included as covariates to identify the unique links between benevolent sexism, anxious attachment, and dependency-oriented support. Results are displayed in Table 9. A significant interaction emerged for gender, benevolent sexism, and attachment avoidance. To further explore the nature of this interaction, another MIXED model was run to simultaneously examine effects split by gender. Findings showed that men's hostile sexism was a significant predictor of dependency-oriented support provision, such that men who more strongly endorsed hostile sexism tended to provide their partners with more dependency-oriented support. The interaction between men's benevolent sexism and attachment avoidance was also significant. A simple slopes analysis revealed that the simple slope for men who were relatively more avoidantly attached (i.e., 1 SD above the mean), $B=-1.38, S E=0.71, t=-1.96, p=.052$, and for men who were relatively less avoidantly attached (i.e., $1 \mathrm{SD}$ below the mean) were marginally significant, $B=-1.02, S E=$ $0.54, t=-1.88, p=.063$. Thus, men who are relatively high in avoidance, tend to provide less dependency-oriented support when they also strongly endorse benevolent sexism (see Figure 3).

A second set of multiple linear regressions were conducted to test the hypothesis that women who more strongly endorse benevolent sexism should be more accepting of their partner's dependency-oriented support (H2a) and that this association is heightened when women are also relatively more anxiously attached $(\mathrm{H} 2 \mathrm{~b})$. Due to statistical power limitations 


\section{Table 9}

Dyadic linear regression using the MIXED procedure regressing dependency-oriented support provision (men) and dependency-oriented support acceptance (women) on sexist beliefs, attachment, and their interactions.

\begin{tabular}{|c|c|c|c|c|c|c|c|c|c|c|c|c|}
\hline \multirow[b]{2}{*}{ Predictors } & \multicolumn{5}{|c|}{ Men } & \multicolumn{5}{|c|}{ Women } & \multicolumn{2}{|c|}{ Gender Difference } \\
\hline & $B$ & CI Low & CI High & $t$ & $p$ & $B$ & CI Low & CI High & $t$ & $p$ & $t$ & $p$ \\
\hline Intercept & 3.49 & 3.23 & 3.76 & 26.0 & $<.001$ & 3.50 & 3.25 & 3.74 & 28.2 & $<.001$ & 3.49 & $<.001$ \\
\hline Benevolent Sexism & -0.03 & -0.32 & 0.26 & -0.20 & .843 & 0.22 & -0.04 & 0.48 & 1.67 & .099 & 0.10 & .347 \\
\hline Hostile Sexism & 0.27 & 0.03 & 0.51 & 2.27 & .026 & 0.02 & -0.18 & 0.23 & 0.22 & .830 & 0.15 & .070 \\
\hline Anxious Attachment & 0.06 & -0.19 & 0.31 & 0.48 & .635 & 0.08 & -0.14 & 0.30 & 0.74 & .465 & 0.07 & .401 \\
\hline Avoidant Attachment & -0.03 & -0.32 & 0.25 & -0.24 & .812 & 0.12 & -0.15 & 0.40 & 0.91 & .368 & 0.05 & .651 \\
\hline BS*Anx & -0.14 & -0.35 & 0.08 & -1.26 & .212 & -0.07 & -0.31 & 0.17 & -0.62 & .541 & -0.03 & .706 \\
\hline HS*Anx & 0.11 & -0.10 & 0.33 & 1.03 & .307 & 0.03 & -0.13 & 0.19 & 0.35 & .727 & 0.04 & .545 \\
\hline BS*Avd & -0.38 & -0.74 & -0.03 & -2.17 & .033 & 0.25 & -0.06 & 0.55 & 1.61 & .112 & -0.32 & .008 \\
\hline HS*Avd & -0.01 & -0.33 & 0.30 & -0.09 & .930 & -0.13 & -0.34 & 0.09 & -1.19 & .239 & 0.06 & .551 \\
\hline
\end{tabular}

Note. Scores for all predictor variables were mean centered. BS = Benevolent Sexism. HS = Hostile Sexism. Anx = Anxious Attachment. Avd $=$ Avoidant Attachment. Effects displayed are estimated for men and women simultaneously while controlling for dependence across partners 


\section{Figure 3}

Simple slopes analysis of the interaction between men's endorsement of benevolent sexism, men's avoidant attachment, and dependency-oriented support provision.

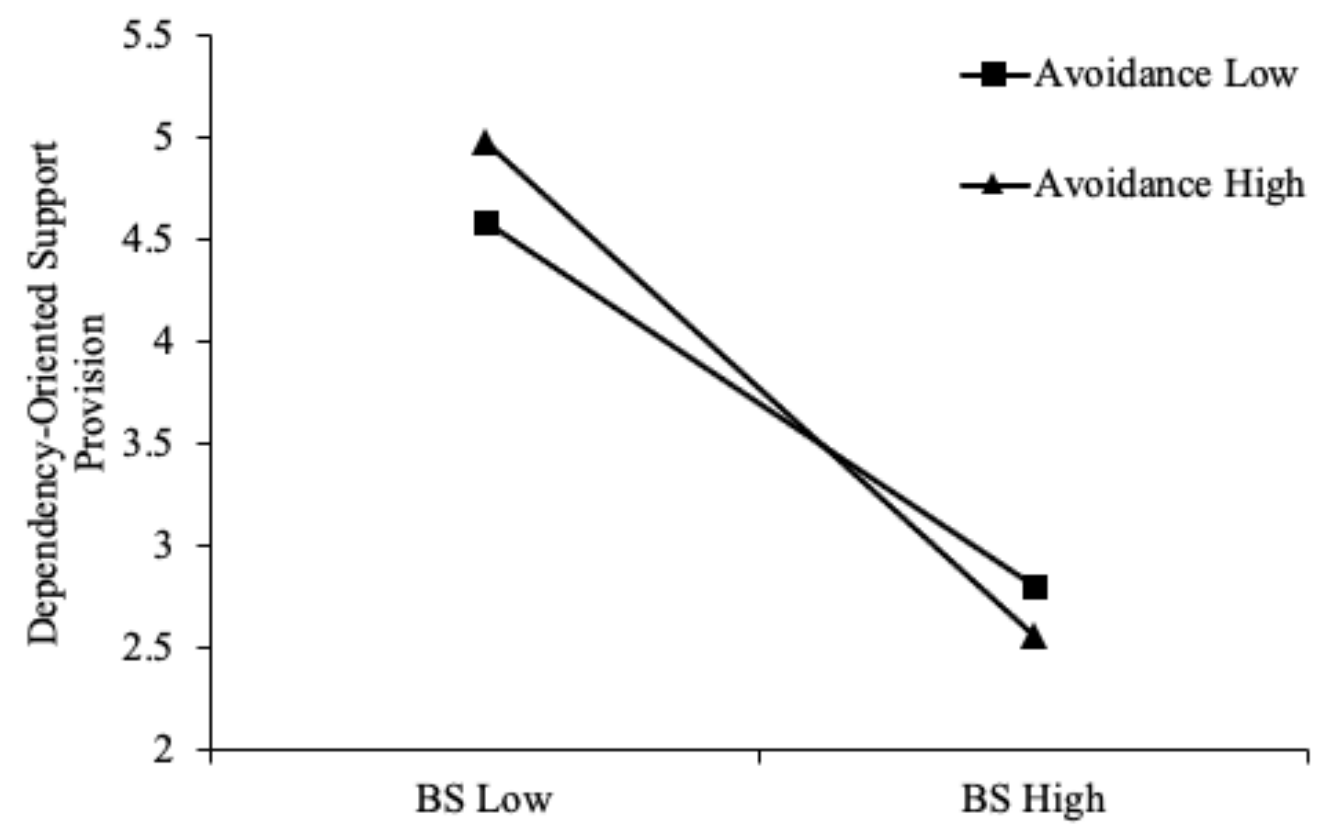

we were unable to test women's acceptance of men's dependency-oriented support in particular, and instead tested women's acceptance of men's support in general. Using the MIXED procedure I regressed acceptance of support on gender, benevolent sexism, and anxious attachment, with hostile sexism and avoidant attachment as covariates. A significant interaction between gender and benevolent sexism emerged, $B=0.22, t(92)=2.25, p=.027$. Upon further analysis (split gender model), men's benevolent sexism and women's benevolent sexism were not significant predictors of support acceptance. The emergence of a significant interaction was due to small effects for men and women in opposite directions; however, the effects independently did not reach significance.

Finally, the last multiple linear regression tested the hypothesis that men who tend to provide dependency-oriented support, and women who tend to accept more of their partner's 
dependency-oriented support will report greater relational need fulfilment (H3a and H3b respectively). Using the MIXED procedure and splitting the model by gender, the first part of the model (testing $\mathrm{H} 3 \mathrm{a}$ ) regressed personal need fulfilment on benevolent sexism, anxious attachment, and dependency-oriented support provision. Results are displayed in Table 10. Men's attachment avoidance was a significant predictor of need fulfilment, such that men who are relatively more avoidantly attached tend to report lower relational need fulfilment, $B$ $=-0.34, t(70)=-2.43, p=.018$. A significant interaction between men's hostile sexism and attachment avoidance also emerged, $B=0.44, t(69)=2.93, p=.005$. A simple slopes analysis revealed that the simple slope for men who are relatively more avoidantly attached (i.e., $1 \mathrm{SD}$ above the mean) was significant, $B=1.59, S E=0.58, t=2.73, p=.007$. The simple slope for men who are relatively less avoidantly attached (i.e., 1 SD below the mean) was also significant, $B=0.83, S E=0.33, t=2.50, p=.013$. Thus, men who are less endorsing of hostile sexism tend to report greater need fulfilment when they are relatively less avoidant, and men who are more endorsing of hostile sexism tend to report even greater need fulfilment regardless of men's level of attachment avoidance (see Figure 4). Using the MIXED procedure and splitting by gender, the second part of the model (testing H3b) regressed partner's need fulfilment on benevolent sexism, anxious attachment, and dependency-oriented support provision. No significant main effects and interactions emerged.

\section{Discussion}

Findings did not support H1a that men who are more endorsing of benevolent sexism would provide their partners with more dependency-oriented support. Instead, a significant main effect emerged for men's hostile sexism, such that men who are more endorsing of hostile sexism tended to provide their partners more dependency-oriented support. This suggests that endorsing an ideology that view that women are incompetent, weak, and 


\section{Table 10}

Multiple linear regression, predicting men's fulfilment of needs when giving dependency-oriented support

\begin{tabular}{|c|c|c|c|c|c|c|c|c|c|c|c|c|}
\hline \multirow[b]{2}{*}{ Predictors } & \multicolumn{5}{|c|}{ Men } & \multicolumn{5}{|c|}{ Women } & \multicolumn{2}{|c|}{ Gender Difference } \\
\hline & $B$ & CI Low & CI High & $t$ & $p$ & $B$ & CI Low & CI High & $t$ & $p$ & $t$ & $p$ \\
\hline Intercept & 5.58 & 5.31 & 5.84 & 41.90 & $<.001$ & 5.49 & 5.18 & 5.80 & 35.70 & $<.001$ & 0.50 & 618 \\
\hline Benevolent Sexism & -0.16 & -0.44 & 0.12 & -1.12 & .267 & -0.06 & -0.38 & 0.26 & -0.39 & .698 & -0.47 & .640 \\
\hline Hostile Sexism & 0.04 & -0.20 & 0.27 & 0.31 & .758 & -0.10 & -0.35 & 0.14 & -0.85 & .397 & 0.87 & .385 \\
\hline Anxious Attachment & 0.03 & -0.21 & 0.26 & 0.24 & .808 & 0.14 & -0.12 & 0.40 & -1.08 & .285 & -0.64 & .525 \\
\hline Avoidant Attachment & -0.34 & -0.61 & -0.06 & -2.43 & .018 & -0.39 & -0.71 & -0.06 & -2.35 & .021 & 0.23 & .815 \\
\hline BS*Anx & -0.16 & -0.36 & 0.05 & -1.50 & .138 & -0.15 & -0.43 & 0.14 & -1.02 & .309 & -0.05 & .957 \\
\hline HS*Anx & -0.12 & -0.33 & 0.09 & -1.17 & .245 & 0.16 & -0.04 & 0.35 & 1.63 & .109 & -1.95 & .053 \\
\hline BS*Avd & -0.26 & -0.60 & 0.08 & -1.50 & .137 & -0.12 & -0.49 & 0.25 & -0.63 & .532 & -0.55 & .584 \\
\hline HS*Avd & 0.44 & 0.14 & 0.74 & 2.93 & .005 & -0.12 & -0.38 & 0.14 & -0.89 & .376 & 2.78 & .006 \\
\hline D/Oriented Support & 0.04 & -0.19 & 0.26 & 0.32 & .749 & -0.10 & -0.38 & 0.18 & -0.69 & .492 & 0.76 & .447 \\
\hline
\end{tabular}

Note. Scores for all predictor variables were mean centered. BS = Benevolent Sexism. $\mathrm{HS}=$ Hostile Sexism. Anx $=$ Anxious Attachment. Avd $=$ Avoidant Attachment. Effects displayed are estimated for men and women simultaneously while controlling for dependence across partners. 


\section{Figure 4}

Simple slopes analysis of the interaction between men's endorsement of hostile sexism, men's avoidant attachment, and need fulfilment.

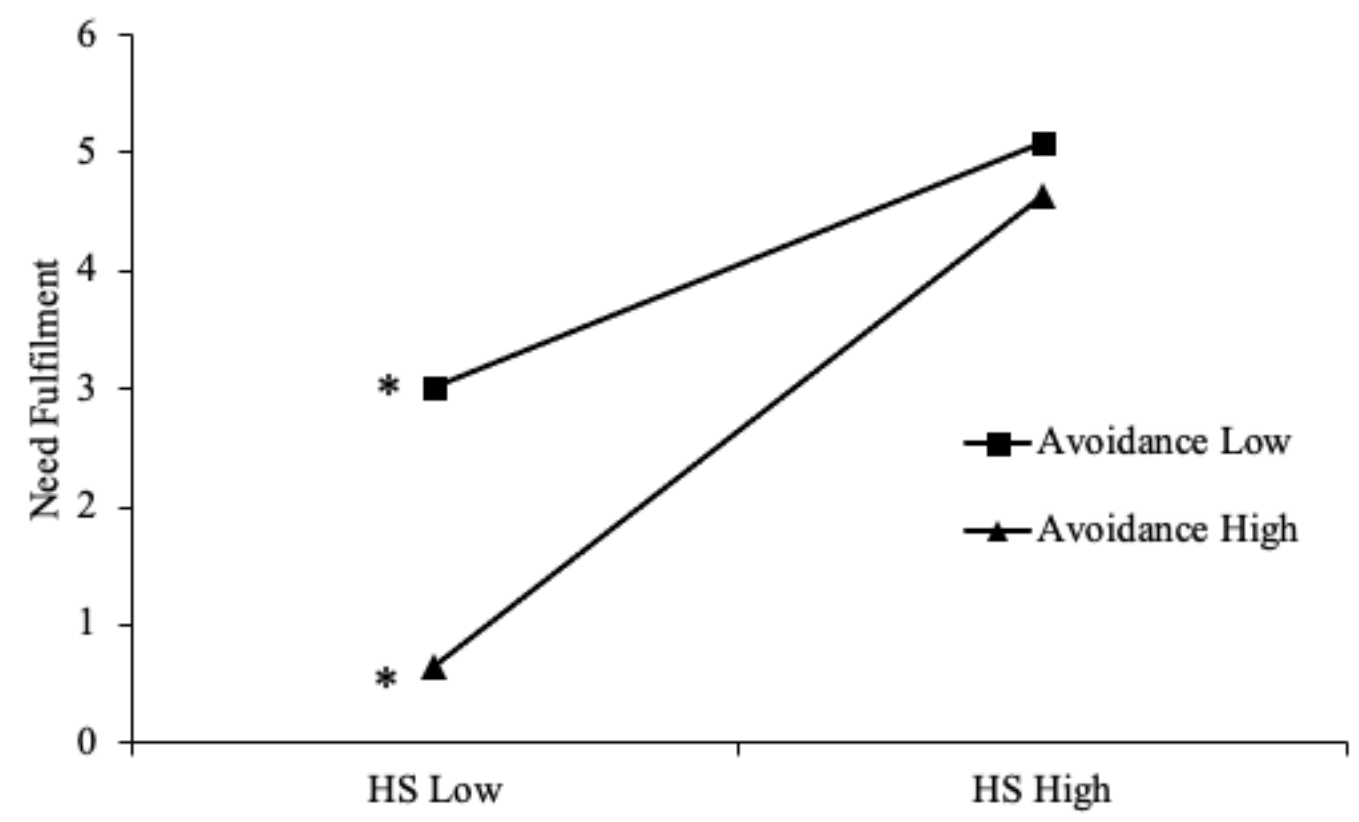

Note. ${ }^{*} p<.05$

sexually manipulative, are linked to greater displays of behaviour that render women dependent upon men for help and support.

The findings of Study 3 did not specifically support H1b, that men who are more endorsing of benevolent sexism and are relatively more anxiously attached would provide their partners with more dependency-oriented support. An interaction, however, did emerge between men's endorsement of benevolent sexism and avoidant attachment; a finding which supports the rationale behind this prediction albeit with a different moderator. For relatively more avoidantly attached men, greater endorsement of benevolent sexism predicted less dependency-oriented support provision. It appears that attachment avoidance dampens the relationship between men's endorsement of benevolent sexism and provision of dependencyoriented support. With reference to attachment theories, this is largely consistent with 
characteristics of avoidantly attached individuals who do not seek dependence within relationships, but rather independence and autonomy (Hazan \& Shaver, 1987; Overall \& Sibley, 2009), and are more likely to avoid giving support during interactions that would foster dependency (Simpson et al., 1992). Although it was predicted that attachment anxiety would exacerbate the relationship between men's endorsement of benevolent sexism and their dependency-oriented support provision (as attachment anxiety is characterised by preoccupations with fulfilling relational needs and fostering dependence), we instead found that attachment avoidance (which is characterised by independence and autonomy) dampens the relationship between men's endorsement of benevolent sexism and their dependency-oriented support provision.

Results are inconclusive for predictions $\mathrm{H} 2 \mathrm{a}$ and $\mathrm{H} 2 \mathrm{~b}$; that women who are more endorsing of benevolent sexism would be more accepting of dependency-oriented support, and that this association would be heightened for relatively more anxiously attached women. Previous research demonstrates a clear link between women's endorsement of benevolent sexism, and women's tendency to ask for direct help and assistance from men, and women's positive appraisals of men's protection of women (Moya et al., 2007; Shnabel et al., 2016). Attachment theory posits that anxious individuals tend to be preoccupied with wanting others to fulfil their core relational needs in adult relationships (Gillath et al., 2016; Hazan \& Shaver, 1987). Seeking, and thus, accepting men's dependency-oriented support was hypothesised a means for women (who are more endorsing of benevolent sexism and are relatively more anxiously attached) to fulfil these needs. However, due to statistical power limitations, only women's general acceptance of support was examined, rather than women's acceptance of men's dependency-oriented support in particular. Thus, while women who more strongly endorse benevolent sexism are no more likely to accept men's support than women who reject benevolent sexism, it is still unclear whether women who more strongly 
endorse benevolent sexism (and are relatively more anxiously attached) tend to be more accepting of men's dependency-oriented support.

Finally, in an attempt to test the functions of dependency-oriented support provision and acceptance in romantic relationships, the results of Study 3 showed that men's provision of dependency-oriented support and women's acceptance of dependency-oriented support did not function to effectively fulfil relational needs, contrary to the prediction of $\mathrm{H} 3 \mathrm{a}$ and $\mathrm{H} 3 \mathrm{~b}$. Thus, the functions of providing and receiving dependency-oriented support are still unclear.

Novel findings did emerge for men. First, it was found that men who are relatively more avoidantly attached tended to report lower need fulfilment. While this was not a prediction of the current study, it is consistent with attachment theories which frame avoidantly attached individuals as being self-reliant within romantic relationships as they tend to hold beliefs that romantic partners (and others in general) are unable to satisfy their own personal needs (Hazan \& Shaver, 1987). Therefore, more avoidantly attached individuals would be more likely to feel less fulfilled in intimate settings and interactions. Secondly, men who are less endorsing of hostile sexism tend to report low need fulfilment when high in avoidance (consistent with attachment theory), and men more endorsing of hostile sexism tend to report high need fulfilment regardless of avoidance levels. Thus, it seems that men who more strongly endorse hostile sexism tend to provide more dependencyoriented support, and men who more strongly endorse hostile sexism also tend to feel more fulfilled after providing women with dependency-oriented support. This novel finding supports the prediction that dependency-oriented support may be a means for men who more strongly endorse hostile sexism to gain power over their relationships and interactions. Providing women with dependency-oriented support may feel fulfilling, as the feelings of power and control gained may be conflated with feelings of intimacy and closeness (Papp et 
al., 2017). I will now discuss in more detail about the pattern of findings across the three studies.

\section{General Discussion}

The current study aimed to weave theories of ambivalent sexism, attachment, and social support to understand the context in which men's chivalry towards women, and women's acceptance of men's chivalry is heightened. Three studies were conducted to examine and test these links. Study 1 and 2 were conducted online and measured men's endorsement of sexism, attachment style, and endorsement of chivalrous dating behaviours. These studies also utilised a word priming task in an attempt to manipulate men's state attachment and establish causality. Study 3 was conducted in-lab, and involved heterosexual couples providing and receiving support while discussing their personal goals with one another.

First, I specifically tested whether men's endorsement of benevolent sexism is linked to greater endorsement and provision of dependency-oriented support behaviours towards women; a relationship that has been shown in prior research (Hammond \& Overall, 2015; Leone et al., 2020; Viki et al., 2003). I predicted that men who more strongly endorsed benevolent sexism would tend to also strongly endorse chivalrous dating behaviours which render women dependent upon men (Study 1 and 2), and men who more strongly endorsed benevolent sexism would provide their partners with more dependency-oriented support (Study 3). Results of Study 1 and 2 showed support for this prediction; men's endorsement of benevolent sexism was positively correlated with their endorsement of chivalrous dating behaviours, and this finding was strengthened by regression analyses which indicated that benevolent sexism was a significant predictor of endorsement of chivalrous dating behaviours. Results of Study 3 showed no support for the prediction that men who more strongly endorse benevolent sexism would provide their partners with more dependency- 
oriented support. Thus, while it is clear that men who more strongly endorse benevolent sexism also support views that men should behave chivalrously towards women, men's actual provision of dependency-oriented behaviours may be context dependent, as Study 3 examined couples interactions when discussing personal goals rather than in a context of dating.

I then tested whether preoccupations with satisfying relational needs (i.e., attachment anxiety) heightens the relationship between men's endorse benevolent sexism and their provision of dependency-oriented support. This was informed by prior research demonstrating links between attachment anxiety and endorsement of benevolent sexism (Hart et al., 2012; Fisher \& Hammond, 2019), and attachment anxiety and dependence (AlonsoArbiol et al., 2002; Cantazaro \& Wei, 2010; Lowyck et al., 2008). I predicted that men who more strongly endorsed benevolent sexism and were relatively more anxiously attached would be more endorsing of chivalrous dating behaviours (Study 1 and 2), and would provide their partners with more dependency-oriented support (Study 3). Furthermore, in Study 1 and 2, I experimentally manipulated men's state attachment (anxious vs. secure) to establish whether preoccupations with satisfying relational needs causes men who more strongly endorse benevolent sexism to also endorse chivalrous dating behaviours. Across all three studies, these hypotheses were either inconclusive due to failed manipulation (Study 1 and 2), or supported with a different moderator (Study 3). No interactions between men's endorsement of benevolent sexism and attachment anxiety emerged when predicting endorsement of chivalrous dating behaviours. However, for men relatively more avoidantly attached, higher endorsement of benevolent sexism predicted less dependency-oriented support provision. This is expected as attachment avoidance is marked by independence and autonomy (and less with preoccupations with relational need fulfilment and dependence). Thus, while attachment anxiety was not found to heighten the relationship between 
benevolent sexism and dependency-oriented support, attachment avoidance was found to dampen the relationship between benevolent sexism and dependency-oriented support instead.

The supplementary prediction that grandiose and vulnerable narcissism—-potential, alternative moderating factors — would heighten the link between men's endorsement of benevolent sexism and their endorsement of chivalrous dating behaviours (Study 2) were not supported. These supplementary findings are inconsistent with research linking motivations to maintain social power and status, and motivations to uphold masculinity norms to chivalrous behaviours (e.g., romantic gift giving and prosocial bystander behaviour at parties; Hyun et al., 2016; Leone et al., 2020). Thus, men who hold the belief that women should be protected, cared for, and provided for, and are more concerned with maintaining status and masculinity within social spheres, are not more likely to endorse chivalrous dating behaviours that increase women's dependence upon men.

In Study 3, I also examined whether women's endorsement of benevolent sexism is linked to greater acceptance of their partner's dependency-oriented support provision during goal discussions; a relationship that has also been demonstrated in previous research (Moya et al., 2007; Shnabel et al., 2016). I predicted that women who more strongly endorse benevolent sexism would also be more accepting on their partner's dependency-oriented support. I also tested whether attachment anxiety moderated this link, as anxiously attached individuals have been shown to want dependence, and behave in ways that foster dependence within their romantic relationships (Alonso-Arbiol et al., 2002; Cantazaro \& Wei, 2010; Lowyck et al., 2008). I predicted that women who more strongly endorse benevolent sexism and who were relatively more anxiously attached would be more accepting of dependencyoriented support. Results from Study 3 were inconclusive, as there was a lack of statistical power needed to test whether women's endorsement of benevolent sexism predicted greater 
acceptance of men's dependency-oriented support, rather than men's general support provision.

Finally, I investigated whether men's provision, and women's acceptance of dependency-oriented support effectively leads to the fulfilment of relational needs. Men's provision of dependency-oriented support is one way of garnering a sense of intimacy and closeness within intimate relationships, fulfilling a relational need for heterosexual men who believe that women are needed to feel complete (Glick \& Fiske, 1996). Similarly, women's acceptance of dependency-oriented support facilitates feelings of security, fulfilling a relational need for heterosexual women who believe that men are supposed to protect and provide for them (Glick \& Fiske, 1996). Thus, I predicted that men who tend to provide more dependency-oriented support, and women who are more accepting of dependency-oriented support would report greater satisfaction of relational needs. Results from Study 3 did not lend support for these predictions, as men who provided relatively more dependency-oriented support were no more likely to report greater fulfilment of needs compared to men who provided relatively less dependency-oriented support. Moreover, women who were relatively more accepting of dependency-oriented support were no more likely to report greater fulfilment of needs compared to women who were relatively less accepting of dependencyoriented support.

Novel findings did appear in the current study. Men who more strongly endorsed hostile sexism were also more likely to endorse chivalrous dating behaviours (Study 2), and also tended to provide more dependency-oriented support (Study 3). The relationship between men's endorsement of hostile sexism and their endorsement of chivalrous dating behaviours was also found to be heightened when men were primed to be more anxiously attached. Novel interactions regarding avoidant attachment, benevolent and hostile sexism, and need fulfilment also emerged. For men relatively more avoidantly attached, higher 
endorsement of benevolent sexism predicted less dependency-oriented support provision. Furthermore, men who are less endorsing of hostile sexism tended to report greater need fulfilment if they were relatively less avoidant, and men who were more endorsing of hostile sexism tended to report even greater need fulfilment regardless of their level of attachment avoidance. The consistency of these results with prior literature and findings, and any alternative explanations will now be discussed.

\section{Research Question 1: The Link Between Men's Benevolent Sexism and Chivalry}

The current studies replicate the positive relationship between men's endorsement of benevolent sexism and dependency-oriented support found in previous research, but also demonstrates that context matters (Hammond \& Overall, 2015; Leone et al., 2020; Viki et al., 2015). Results of Study 1 and Study 2 showed that men's endorsement of benevolent sexism was positively linked to their endorsement of chivalrous dating behaviours. Study 3 however, showed no significant associations between men's endorsement of benevolent sexism and their actual dependency-oriented support provision. This points to differences between men's endorsement of chivalrous, dependency-oriented support behaviours within a dating context, versus within general support contexts in established romantic relationships. The relationship between men's and women's endorsement of benevolent sexism, and their provision and acceptance of dependency-oriented support may be more consistently demonstrated in situations marked by romance rather than support scenarios in general (Lamy et al., 2009; Yoder et al., 2002). For example, men are more likely to extend chivalrous, helping behaviours to women when they have been primed with ideas of love (Lamy et al., 2009). It has also been shown that while women are more likely to hold doors open for men in general, men are more likely to hold doors open for women in dating contexts (Yoder et al., 2002). Thus, benevolently sexist ideologies may only inform the provision/acceptance of chivalrous, dependency-oriented behaviours during scenarios where romance is heightened and gender 
roles are salient; reinforcing the notion that chivalry is a means of establishing relationships rather than maintaining them, and that men should be the ones to extend chivalrous helping behaviours towards women.

Current study findings suggest that a lack of attachment avoidance rather than greater attachment anxiety moderates the relationship between men's endorsement of benevolent sexism and their dependency-oriented support provision. Results across the three studies did not lend support to attachment anxiety being a moderating variable, and failed to establish attachment anxiety as a causal mechanism between men's endorsement of benevolent sexism and endorsement of chivalrous dating behaviours. Prior research has demonstrated links between men's attachment anxiety and endorsement of benevolent sexism (Fisher \& Hammond, 2019; Hart et al., 2012), and men who are relatively more anxiously attached tend to seek reassurance and crave dependency within romantic relationships (Alonso-Arbiol et al., 2002; Cantazaro \& Wei, 2010; Lowyck et al., 2008). More anxiously attached men should therefore, be more endorsing of benevolent sexism as it encompasses the view that men "need a women's love to feel complete" (Glick \& Fiske, 1997; Fisher \& Hammond, 2019), and should also behave in ways (or endorse behaviours) that facilitate feelings of dependency (Overall et al., 2014). In particular, behaviours that render women dependent on men. However, an interaction emerged between benevolent sexism and avoidant attachment, such that for men relatively more avoidantly attached, higher endorsement of benevolent sexism predicts less dependency-oriented support provision. More avoidantly attached individuals tend to avoid interactions that foster dependence and seek independence and autonomy within their relationships (Hazan \& Shaver, 1987; Overall \& Sibley, 2009; Simpson et al., 1992) which can explain why even men who tend to hold benevolently sexist views provide less dependency-oriented support. By examining avoidant attachment as a covariate, we were able to identify that it may be the lack of attachment avoidance (rather 
than greater levels of attachment anxiety) that heightens men's (who more strongly endorse benevolent sexism) tendency to behave in chivalrous, dependency-oriented ways.

Novel findings from the current studies show that hostile sexism may also prompt men to behave in chivalrous ways. The emergence of hostile sexism as a predictor of providing more dependency-oriented support and greater endorsement of chivalrous dating behaviours, and its interactions with anxious attachment were unexpected findings that have not been illustrated in previous literature thus far. One explanation for this is that men who more strongly endorse hostile sexism may employ the use of dependency-oriented support giving as a means to 'disarm' women to regain power over the interaction (Jackman, 1994). While men who more strongly endorse hostile sexism tend to hold biased perceptions that they generally hold less power within their relationships (Cross et al., 2019), this may be heightened when men are relatively more insecure, in situations designed to put men in the position of lesser power and control, and situations where partners' dependence or commitment to the relationship comes into question (Cross et al., 2017; Overall et al., 2016). For example, when men are more anxiously attached, and are discussing their partner's independent goal pursuits. Strategies that strongly imply women's lack of autonomy and competence such as explicitly giving direct advice/instruction, showing concerns over partners' ability to achieve their goals, and taking over the conversation (Hammond \& Overall, 2015), could be considered strategies that are more persuasive and effective for regaining control and security, than outright aggression which may impede men's fulfilment of their relational needs (Hammond \& Overall, 2017; Jackman, 1994; Overall et al., 2011). Thus, even men who more strongly endorse hostile sexism may be motivated to behave chivalrously when their relational power is threatened.

\section{Research Question 2: The Link Between Women's Benevolent Sexism and Chivalry}


Findings that examined the relationship between women's endorsement of benevolent sexism and acceptance of chivalry indicate that women's acceptance may be contextdependent. While the results of Study 3 could not conclude whether women who more strongly endorse benevolent sexism are also more accepting of their partner's dependencyoriented support, the findings lend no support to the relationship between women's endorsement of benevolent sexism and their acceptance of their partner's general support provision. This is somewhat inconsistent with existing research demonstrating that women who more strongly endorse benevolent sexism (encompassing beliefs that women should be protected and cared for by men) tend to react positively and in some situations even seek dependency-oriented support from men, especially if the men are romantic partners (Moya et al., 2007; Shnabel et al., 2016). Findings also showed no support for the moderating role of attachment, contrary to key assumptions of attachment theory. Within heterosexual romantic relationships, women who are relatively more anxiously attached tend to be more preoccupied with wanting men to fulfil their core relational needs, and accepting men's dependency-oriented was predicted to be a means of achieving this (Gillath et al., 2016; Hazan \& Shaver, 1987).

Study 3 however, differs from these studies that have shown a link between women's endorsement of benevolent sexism and their acceptance of men's support. Both the Moya et al. (2007) and Shnabel et al. (2016) studies mainly utilised hypothetical support scenarios (e.g., imagining that women were put in a dangerous situation), and were largely impersonal (e.g., help with a logic puzzle), whereas Study 3 required participants to divulge their personal goals and aspirations in a real support scenario with their partners. It is plausible that women who more strongly endorse benevolent sexism are less likely to show outward acceptance of their partners dependency-oriented support when it is in reference to their independent goal pursuits. Hammond and Overall (2015), who used the same goal-discussion 
paradigm, found that women who received dependency-oriented support from their partners tended to feel less competent and less regarded after the interaction. Feeling less competent and regarded may in turn, diminish any positive reactions, appraisals, and expressions of acceptance women may demonstrate during the interaction.

Study 3 was also different, in that the goal-discussion paradigm does not intend to raise issues surrounding potential harm and danger. Situations such as hypothetical internship counselling dangerous criminals (Moya et al., 2007) may evoke stronger protective reasoning from men. As a result, dependency-oriented support may be more justified and accepted by women who endorse benevolent sexism, as they believe men should protect and care for women when they are in (potential) danger. Thus, when women's independent goal pursuits are at stake and the situation does not evoke feelings of potential danger, even women who more strongly endorse benevolent sexism may be just as accepting of their partner's support as women who reject benevolent sexism. The current study points to the importance of replicating results from existing literature, and utilising methodologies which position women in various support scenarios (i.e., ones that are not inherently dangerous or impersonal), as women's acceptance of support may be conditional upon this.

\section{Research Question 3: Need Fulfilment as a Consequence of Dependency-Oriented}

\section{Support}

When examining fulfilment of relational needs as a consequence of men's provision, and women's acceptance of dependency-oriented support, the current findings suggests that feeling relationally fulfilled may also be dependent upon endorsement of benevolent sexism. The prediction that men's dependency-oriented support provision functions to fulfil relational needs was not met by Study 3 results. This prediction was informed by weaving theories of ambivalent sexism, attachment, and social support. However, due to statistical power limitations, the current study did not test interactions between men's dependency-oriented 
provision, endorsement of benevolent sexism, and attachment anxiety. Providing dependency-oriented support should confer benefits for men who endorse benevolent sexism by subtly reinforcing their competence and authority (Glick \& Fiske, 1996), and should also act to facilitate intimacy and closeness in their relationships to alleviate concerns with rejection and abandonment for those who are relatively more anxiously attached (Hammond et al., 2015; Overall et al., 2014). Thus, men's dependency-oriented support provision may only fulfil relational needs if they also endorse benevolent sexism, and/or are relatively more anxiously attached.

The hypothesis that women's acceptance of dependency-oriented support would predict increases in need fulfilment was also unmet. Accepting men's dependency-oriented support should confer benefits for women by giving access to men's protection and care, whilst simultaneously facilitating dependency in relationships (Moya et al., 2007; Shnabel et al., 2016). Similarly, the current study did not test the interactions between women's endorsement of sexist beliefs and their acceptance of dependency-oriented support when predicting need fulfilment. Women who more strongly endorse benevolent sexism believe that they should be cared for, provided for, and protected by men (Glick \& Fiske, 1996). These women are concerned with reaping the benefits of benevolent sexism (such as men's protection and reverence) and tend to be more accepting of it when their partners also endorse similar ideologies (Hammond et al., 2016). Thus, accepting dependency-oriented support may only fulfil women's relational needs, only when women also hold benevolently sexist beliefs.

Another alternative explanation could be that men's dependency-oriented support provision is a means of gaining power in the interaction, rather than to satisfy relational needs. Dependency-oriented support negates women's abilities and undermines their independence (Hammond \& Overall, 2015), but is often romantic sounding (and has 
protective intentions in some cases; Moya et al., 2007), making it a covert, soft strategy that is more likely to foster successful interactions compared to explicitly demeaning women's capabilities (Overall et al., 2011). Gaining power should be particularly salient for men who endorse hostile sexism, as men who more strongly endorse hostile sexism believe that men are more competent and agentic compared to women, and view powerful women as being manipulative (Glick \& Fiske, 1996). Findings have also shown that men who more strongly endorse hostile sexism tend to have biased perceptions of their own power within intimate relationships, such that they perceive themselves as holding less power than their partners (Cross et al., 2018). Thus, dependency-oriented support provision may also be a technique that men who more strongly endorse hostile sexism utilise in order to alleviate these power concerns.

\section{Theoretical and Practical Implications}

These findings have implications for ambivalent sexism theory. According to ambivalent sexism theory, individuals who endorse benevolent sexism tend to hold beliefs that women should be protected, cherished, and provided for by men (Glick \& Fiske, 1996). Such beliefs have been linked to men's chivalrous behaviours (Viki et al., 2003), men's provision of dependency-oriented support (Hammond et al., 2015), women's positive appraisals of dependency-oriented support (Moya et al., 2007), and women's preference for dependency-oriented support (Shnabel et al., 2016). The current study results solidify the links between men's endorsement of benevolent sexism and their endorsement of chivalrous dating behaviours which render women dependent upon men. However, men who more strongly endorse benevolent sexism do not tend to give more dependency-oriented support in scenarios where couples are giving each other support while discussing personal goal pursuits. Thus, despite being "support" behaviours, acting chivalrously in a dating context, and providing dependency-oriented support during couples discussions appear to be 
qualitatively different. Similarly, the current study results showed no support for the predicted relationship between women's endorsement of benevolent sexism and their acceptance of men's dependency-oriented support during discussions of personal goals. The relationship between men's and women's endorsement of benevolent sexism, and their provision and acceptance of dependency-oriented support may be more consistently demonstrated in situations where romance, courtship, and gender roles are salient, compared to more general support contexts found in established relationships (Lamy et al., 2009; Yoder et al., 2002). Therefore, holding the belief that men should protect, care for, and provide for women may only inform men's provision and women's acceptance of chivalry during courtship or dating. This supports the idea that dependency-oriented support may be a means of establishing relational bonds, rather than maintaining relationships and fulfilling relational needs in general.

The current results also uncovered a relationship between men's endorsement of hostile sexism and provision of dependency-oriented support. While ambivalent sexism theory posits that those who endorse hostile sexism hold the belief that women are incompetent, inferior, and manipulative temptresses (Glick \& Fiske, 1996), these same beliefs may also lead to men providing women with more dependency-oriented help in order to gain power and control covertly. Dependency-oriented behaviours such as giving women direct advice, paying for dates, and protecting women from other men, is a subtle yet efficient way for men who more strongly endorse hostile sexism to show off social status and maintain power within the relationship, as opposed to behaviours such as directly criticising or demeaning women (Jackman, 1994). Therefore, ambivalent sexism theory may need to consider that hostile sexist beliefs can also inform romantic-sounding behaviours.

In conjunction with ambivalent sexism theory, the current study also has implications for attachment theory. Previous literature examining the relationship between individual's 
endorsement of benevolent and hostile sexism, and their attachment style illustrate that greater attachment anxiety is related to greater endorsement of both hostile and benevolent sexism; whereas, greater attachment avoidance is related to greater endorsement of hostile, but not benevolent sexism (Fisher \& Hammond, 2019; Hart et al., 2012). Although the prediction that attachment anxiety would heighten the link between men's/women's endorsement of benevolent sexism and their provision/acceptance of dependency-oriented support, the current study provides insight on patterns of behaviours that emerge when men are relatively more avoidant and more strongly endorse benevolent sexism - an interaction which is unlikely according to previous research. Even men who hold the belief that women should be protected, cherished, and provided for may not present women with the dependency-oriented support that is expected of them-especially if they also hold beliefs that relational dependence may inhibit independence, or lead to abandonment or rejection. Thus, greater attachment anxiety may not necessarily heighten the relationship between benevolent sexism and dependency-oriented support, but rather a lack of avoidance dampens the relationship between benevolent sexism and dependency-oriented support.

When predicting men's chivalrous, dependency-oriented support and women's acceptance of such behaviours, it is important to not only consider their beliefs on gender roles and expectations, but also the contexts in which the behaviours are embedded in, as well as the relational schemas they have formed throughout adulthood. Behaviours such as holding doors open for women on a date, giving direct advice and solutions, and protecting women from other dangerous men may be utilised more so in contexts where romance is salient to establish rather than maintain relationships (e.g., during the dating stages of a relationship). However, chivalrous behaviours may also be utilised as a covert strategy if motivated by power and control concerns, especially for men who are more endorsing of hostile sexism. Although men who endorse benevolent sexism should behave more 
chivalrously towards women, these behaviours can be inhibited by beliefs that frame relational dependence as negative, and a potential catalyst for rejection and abandonment.

\section{Strengths, Constraints on Generalisability, and Future Directions}

The current study had many strengths to it. In terms of expanding theory and outlook, the current study links ambivalent sexism and attachment theory to examine the conditions under which men are more likely to utilise and women more likely to accept dependencyoriented support (i.e., why do some men tend to behave chivalrously and why are some women are more accepting of it than others?). Previous research shows that preoccupations with fulfilling relational needs (i.e., attachment anxiety) are linked to traditional relationship beliefs (i.e., benevolent sexism; Fisher \& Hammond, 2019; Hart et al., 2012), and that these factors independently are associated with dependency and chivalrous support behaviours that render women dependent on men (Alonso-Arbiol et al., 2002; Cantazaro \& Wei, 2010; Hammond \& Overall, 2015; Lowyck et al., 2008; Moya et al., 2007; Shnabel et al., 2016; Viki et al., 2003). However, there are no studies to date that test the relationship between these key variables. Moreover, the current study also examined the functions of dependencyoriented support provision and acceptance, by testing whether the fulfilment of relational needs was a consequence of men providing, and women accepting dependency-oriented support.

By utilising both experimental and naturalistic observation methods, I was able to investigate whether the key moderating variable (attachment style) could be manipulated to establish causality. That is, whether manipulating men to be relatively more anxiously attached would cause men who more strongly endorse benevolent sexism to be more endorsing of dependency-oriented support and chivalrous dating behaviours. By following these results up with observations of couples during a goal discussion, I could also investigate whether these effects translated to a more ecologically valid situation, and compare and 
contrast men's endorsement versus their actual provision of dependency-oriented support. For example, the current study results showed that while men who more strongly endorse benevolent sexism tend to also strongly endorse dependency-oriented dating behaviours, the same association was found for actual provision of dependency-oriented support in couples' interactions with one another, but conditional upon their levels of attachment avoidance.

While women's support giving has been a point of focus in some studies (Hammond \& Overall, 2015), there are few studies which examines women's responses to different types of support. The existing studies which do examine this, often measure women's appraisal of the support after-the-fact, utilise hypothetical interactions with partners, or employ the help of male confederates or strangers (Moya et al., 2007; Shnabel et al., 2016). The current study (specifically Study 3) measured and observed women's actual behavioural responses to their romantic partners' support provision during an interaction where they are discussing personal goals. This is particularly important, as prior research shows women's endorsement of sexist beliefs are inextricably linked with perceptions of their partner's endorsement of sexist beliefs (Hammond et al., 2016).

There were however, several limitations to the current study which may prevent these results from being generalised to the wider population of heterosexual, cisgender men and women. Firstly, the dating beliefs and expectations that were presented to participants in Study 1 and Study 2 may not be reflective of all cultural and contemporary dating/courtship norms. Dependency-oriented behaviours may be more salient and acceptable in countries high in gender inequality, as women being dependent upon men for support is a normative belief (Glick et al., 2000). In these countries/cultures with a high degree of gender inequality, women would also be more motivated to reap the benefits and rewards of endorsing and abiding by benevolently sexist views and norms (e.g., to gain men's protection and support; Glick et al., 2000). In more egalitarian countries where men are more likely to support 
women's liberation movements, chivalry is less commonly extended towards women (Young et al., 1975). Thus, we should expect the relationship between benevolent sexism and chivalry to be more pronounced in countries marked by inequality, and for women in particular to feel fulfilled after receiving dependency-oriented support.

Secondly, studies have shown that benevolent sexism and chivalrous behaviours are conditionally applied according to the race of the recipient. For example, benevolently sexist views are applied more towards white women compared to black women, and the endorsement of benevolent sexism is linked to increased victim blaming and reduced willingness to help black women in danger compared to white women (Katz et al., 2018; McMahon \& Kahn, 2015). Even when profiles of black women are framed to be more in line with traditional feminine roles, they are no more likely to be positively appraised compared to white women (McMahon \& Kahn, 2015). Similarly, appraisals of men's benevolent sexism also differ with race. For example, individuals are more likely to appraise a black man's paternalistic behaviour as more sexist, compared to a white man's paternalistic behaviour (Kirkman \& Oswald, 2019). Future studies should thus, examine the intersection between men's dependency-oriented support provision and the race of the support recipient, as well as women's acceptance of dependency-oriented support and the race of the support provider. It may be that men's chivalry is only extended to white women as they are deemed to be "more traditionally feminine", and women may only be accepting of white men's chivalry as they are perceived to be "more caring and romantic" (Kirkman \& Oswald, 2019; McMahon \& Kahn, 2015).

In terms of methodology, there were also limitations that need to be addressed, should these studies be replicated in the future. First, due to Covid-19 restrictions, Study 1 and Study 2 were unable to be run with an in-lab sample. This meant that participants could only complete online surveys regarding their endorsement of sexist beliefs and chivalrous dating 
behaviours, and the priming task used to manipulate men's state attachment was also completed online in an uncontrolled environment. This specific word unscrambling task was chosen due to its unassuming and covert nature. Another widely used paradigm in the attachment literature that manipulates participants' attachment styles momentarily — the WHOTO procedure - requires participants to recall their interactions/relationships with those close to them, and is thus, more likely to inform participants of the true nature of the study (Fraley \& Davis, 1997). Previous studies which have utilised the word unscrambling manipulation task have done so in a controlled lab environment free of distractions (Finkel et al., 2007; Gillath et al., 2006; Green \& Campbell, 2000). These studies were also successful in manipulating men's state attachment whereas the current study failed manipulation checks. Thus, future replications should ensure the questionnaires and manipulation task are completed in a controlled environment, followed up with a manipulation check to assess the success of the priming.

It may also be worthwhile to examine men's provision and women's acceptance of dependency-oriented support over a longer period of time, to see whether need fulfilment manifests as a long-term consequence rather than a momentary effect after each support interaction. Longitudinal, daily diary studies can be utilised to investigate this possibility in the future (see Hammond \& Overall, 2013; Overall et al., 2016).

\section{Conclusion}

Relationship research has shown that men's endorsement of benevolent sexism is linked to chivalrous support behaviours, and women's endorsement of benevolent sexism is linked to positive appraisals of these behaviours because they bring relational benefits, despite undermining women's competence and autonomy. Relationship theories also posit that anxiously attached individuals should be motivated to satisfy their relational needs, and should therefore endorse views and behave in ways that facilitate the fulfilment of these 
needs. To date, no study has weaved these theories of ambivalent sexism, attachment, and support to examine why some men behave chivalrously and why some women are more accepting of it than others. The current study investigated whether attachment anxiety moderates the link between men's endorsement of benevolent sexism and their dependencyoriented support provision, and between women's endorsement of benevolent sexism and their acceptance of dependency-oriented support. This study also tested whether the fulfilment of relational needs is a consequence of men providing, and women accepting dependency-oriented support. Results consistently demonstrated the existing link between men's endorsement of benevolent sexism and endorsement of chivalrous dating behaviours, however, results for women were inconsistent with previous literature. Predictions about the role of attachment anxiety and need fulfilment were either inconclusive or unmet. Novel findings suggest that hostile sexism may motivate men's chivalrous behaviours and that attachment avoidant (rather than attachment anxiety) may moderate the link between benevolent sexism and dependency-oriented support. Furthermore, distinctions should be made between romantic support scenarios and general support scenarios. Chivalrous, dependency-oriented support behaviours are inexplicably intertwined with beliefs about gender roles and expectations, schemas about relationships and dependence, and the contexts in which they are presented in. Ambivalent sexism, attachment, and support theories must be integrated to examine why these behaviours occur and what functions they serve. 


\section{References}

Abrams, D., Viki, T., Masser, B., Bohner, G. (2003). Perceptions of stranger and acquaintance rape: The role of benevolent and hostile seism in victim blame and rape proclivity. Journal of Personality and Social Psychology, 84, 111-125. https://doi.org/10.1037/0022-3514.84.1.111

Adamczyk, K., \& Segrin, C. (2015). Perceived social support and mental health among single vs. partnered Polish young adults. Current Psychology, 34(1), 82-96. https://doi.org/10.1007/s12144-014-9242-5

Ainsworth, M. D., \& Bell, S. M. (1970). Attachment, exploration, and separation: Illustrated by the behavior of one-year-olds in a strange situation. Child Development, 41(1), 4967. https://doi.org/10.2307/1127388

Alonso-Arbiol, I., Shaver, P. R., \& Yárnoz, S. (2002). Insecure attachment, gender roles, and interpersonal dependency in the Basque Country. Personal Relationships, 9(4), 479490. https://doi.org/10.1111/1475-6811.00030

Bosson, J. K., Pinel, E. C., \& Vandello, J. A. (2010). The emotional impact of ambivalent sexism: Forecasts versus real experiences. Sex Roles, 62(7-8), 520-531. http://doi.org/10.1007/s11199-009-9664-y

Bowlby, J. (1999). Attachment and loss (2nd ed). Basic Books.

Cantazaro, A., \& Wei, M. (2010). Adult attachment, dependence, self-criticism, and depressive symptoms: A test of a mediational model. Journal of Personality, 78(4), 1135-1162. https://doi.org/10.1111/j.1467-6494.2010.00645.x

Cohen, J. (1988). Statistical power analysis for the behavioral sciences, (2nd ed.). Routledge.

Cohen, S., \& Wills, T. A. (1985). Stress, social support, and the buffering hypothesis. Psychological Bulletin, 98(2), 310-357. https://doi.org/10.1037/0033-2909.98.2.310 
Connelly, K., \& Heesacker, M. (2012). Why is benevolent sexism appealing? Associations with system justification and life satisfaction. Psychology of Women Quarterly, 36(4), 432-443. https://doi.org/10.1177/0361684312456369

Connor, R. A., \& Fiske, S. T. (2019). Not minding the gap: How hostile sexism encourages choice explanations for the gender income gap. Psychology of Women Quarterly, 43(1), 22-36. https://doi.org/10.1177/0361684318815468

Cramer, D. (2007). How a supportive partner may increase relationship satisfaction. British Journal of Guidance and Counselling, 34(1), 117-131. https://doi.org/10.1080/03069880500483141

Cross, E. J., \& Overall, N. C. (2018). Women's attraction to benevolent sexism: Needing relationship security predicts greater attraction to men who endorse benevolent sexism: Women's attraction to benevolent sexism. European Journal of Social Psychology, 48(3), 336-347. https://doi.org/10.1002/ejsp.2334

Cross, E. J., \& Overall, N. C. (2019). Women experience more serious relationship problems when male partners endorse hostile sexism. European Journal of Social Psychology, 49(5), 1022-1041. https://doi.org/10.1002/ejsp.2560

Cross, E. J., Overall, N. C., Hammond, M. D., \& Fletcher, G. J. O. (2017). When does men's hostile sexism predict relationship aggression? The moderating role of partner commitment. Social Psychological and Personality Science, 8(3), 331-340. https://doi.org/10.1177/1948550616672000

Cross, E. J., Overall, N. C., Low, R. S. T., \& McNulty, J. K. (2019). An interdependence account of sexism and power: Men's hostile sexism, biased perceptions of low power, and relationship aggression. Journal of Personality and Social Psychology, 117(2), 338-363. https://doi/org/10.1037/pspi0000167 
Dandurand, C., Bouaziz, A. R., \& Lafontaine, M. F. (2013). Attachment and couple satisfaction: The mediating effect of approach and avoidance commitment. Journal of Relationships Research, 4, Article e3. https://doi.org/10.1017/jrr.2013.3

Dardenne, B., Dumont, M., \& Bollier, T. (2007). Insidious dangers of benevolent sexism: Consequences for women's performance. Journal of Personality and Social Psychology, 93(5), 764-779. http://doi.org/10.1037/0022-3514.93.5.764

Davila, J., \& Bradbury, T. N. (2001). Attachment insecurity and the distinction between unhappy spouses who do and do not divorce. Journal of Family Psychology, 15(3), 371-393. https://doi.org/10.1037/0893-3200.15.3.371

Davis, L., \& Brekke, J. (2014). Social support and functional outcome in severe mental illness: The mediating role of proactive coping. Psychiatry Research, 215(1), 39-45. https://doi.org/10.1016/j.psychres.2013.09.010

Delacollette, N., Dumont, M., Sarlet, M., \& Dardenne, B. (2013). Benevolent sexism, men's advantages and the prescription of warmth to women. Sex Roles, 68(5-6), 296-310. http://doi.org/10.1007/s11199-012-0232-5

Faul, F., Erdfelder, E., Buchner, A., \& Lang, A. G. (2009). Statistical power analyses using G*Power 3.1: Tests for correlation and regression analyses. Behaviour Research Methods, 41, 1149-1160. https://doi.org/10.3758/BRM.41.4.1149

Feeney, J. A., \& Noller, P. (1990). Attachment style as a predictor of adult romantic relationships. Journal of Personality and Social Psychology, 58(2), 281-291. https://doi.org/10.1037/0011-3514.58.2.281

Finkel, E. J., Burnette, J. L., \& Scissors, L. E. (2007). Vengefully ever after: Destiny beliefs, state attachment anxiety, and forgiveness. Journal of Personality and Social Psychology, 92(5), 871-886. https://doi.org/10.1037/0022-3514.92.5.871 
Fisher, M. I., \& Hammond, M. D. (2019). Personal ties and prejudice: A meta-analysis of romantic attachment and ambivalent sexism. Personality and Social Psychology Bulletin, 45(7), 1084-1098. https://doi.org/10.1177/0146167218804551

Fraley, R. C., \& Davis, K. E. (1997). Attachment formation and transfer in young adults' close friendships and romantic relationships. Personal Relationships, 4(2), 131-144. https://doi.org/10.1111/j.1475-6811.1997.tb00135.x

Fraser, G., Osborne, D., \& Sibley, C. G. (2015). "We want you in the workplace, but only in a skirt!" Social dominance orientation, gender-based affirmative action and the moderating role of benevolent sexism. Sex Roles, 73(5-6), 231-244. http://doi.org/10.1007/s11199-015-0515-8

Gentile, B., Miller, J. D., Hoffman, B. J., Reidy, D. E., Zeichner, A., \& Campbell, W. K. (2013). A test of two brief measures of grandiose narcissism: The Narcissistic Personality Inventory-13 and the Narcissistic Personality Inventory-16. Psychological Assessment, 25(4), 1120-1136. https://doi.org/10.1037/a0033192

Gillath, O., Karantzas, G. C., \& Fraley, R. C. (2016). What Are Attachment Working Models? In O. Gillath, G. C. Karantzas, \& R. C. Fraley (Eds.), Adult Attachment (pp. 77-101). Academic Press. https://doi.org/10.1016/B978-0-12420020-3.00004-9

Gillath, O., Mikulincer, M., Fitzsimmons, G. M., Shaver, P. R., \& Schachner, D. A. (2006). Automatic activation of attachment-related goals. Personality and Social Psychology Bulletin, 32(10), 1375-88. https://doi.org/10.1177/0146167206290339

Glick, P., \& Fiske, S. T. (1996). The ambivalent sexism inventory: Differentiating hostile and benevolent sexism. Journal of Personality and Social Psychology, 70(3), 491-512. https://doi.org/10.1037/0022-3514.70.3.491 
Glick, P., \& Fiske, S. T. (2001). An ambivalent alliance: Hostile and benevolent sexism as complementary justifications for gender inequality. American Psychologist, 56(2), 109-118. http://doi.org/10.1037/0003-066X.56.2.109

Glick, P., Fiske, S. T., Mladinic, A., Saiz, J. L., Abrams, D., Masser, B., Adetoun, B., Osagie, J. E., Akande, A., Alao, A., Annetje, B., Willemsen, T. M., Chipeta, K., Dardenne, B., Dijksterhuis, A., Wigboldus, D., Eckes, T., Six-Materna, I., Expósito, F., ... López, W. L. (2000). Beyond prejudice as simple antipathy: Hostile and benevolent sexism across cultures. Journal of Personality and Social Psychology, 79(5), 763-775. http://doi.org/10.1037/0022-3514.79.5.763

Grabe, M. E., Trager, K. D., Lear, M., \& Rauch, J. (2006). Gender in crime news: A case study test of the chivalry hypothesis. Mass Communication \& Society, 9(2), 137-163. http://doi.org/10.1207/s15327825mcs0902_2

Green, J. D., \& Campbell, W. K. (2000). Attachment and exploration in adults: Chronic and contextual accessibility. Personality and Social Psychology Bulletin, 26(4), 452-461. https://doi.org/10.1177/0146167200266004

Gul, P., \& Kupfer, T. R. (2019). Benevolent sexism and mate preferences: Why do women prefer benevolent men despite recognising that they can be undermining? Personality and Social Psychology Bulletin, 45(1), 146-161. https://doi.org/10.1177/0146167218781000

Hammond, M. D., \& Overall, N. C. (2013). Men's hostile sexism and biased perceptions of intimate partners: Fostering dissatisfaction and negative behavior in close relationships. Personality and Social Psychology Bulletin, 39(12), 1585-1599. https://doi.org/10.1177/0146167213499026

Hammond, M. D., \& Overall, N. C. (2015). Benevolent sexism and support of romantic partner's goals: Undermining women's competence while fulfilling men's intimacy 
needs. Personality and Social Psychology Bulletin, 41(9), 1180-1194.

https://doi.org/10.1177/0146167215593492

Hammond, M. D., \& Overall, N. C. (2017). Dynamics within intimate relationships and the causes, consequences, and functions of sexist attitudes. Current Directions in Psychological Science, 26(2), 120-125. https://doi.org/10.1177/0963721416686213

Hammond, M. D., Overall, N. C., \& Cross, E. J. (2016). Internalizing sexism within close relationships: Perceptions of intimate partners' benevolent sexism promote women's endorsement of benevolent sexism. Journal of Personality and Social Psychology, 110(2), 214-238. http://doi.org/10.1037/pspi0000043

Hammond, M. D., \& Sibley, C. G. (2011). Why are benevolent sexists happier? Sex Roles, 65(5-6), 332-343. http://doi.org/10.1007/s11199-011-0017-2

Hammond, M. D., Sibley, C. G., \& Overall, N. C. (2013). The allure of sexism. Social Psychological and Personality Science, 5(4), 422-429. https://doi.org/10.1177/1948550613506124

Hart, J., Hung, J. A., Glick, P., \& Dinero, R. E. (2012). He loves her, he loves her not: Attachment style as a personality antecedent to men's ambivalent sexism. Personality and Social Psychology Bulletin, 38(11), 1495-1505. http://doi.org/10.1177/0146167212454177

Hazan, C., \& Shaver, P. (1987). Romantic love conceptualized as an attachment process. Journal of Personality and Social Psychology, 52(3), 511-524. http://doi.org $/ 10.1037 / 0022-3514.52 .3 .511$

Hendin, H. M., \& Cheek, J. M. (1997). Assessing hypersensitive narcissism: A reexamination of Murray's Narcissism Scale. Journal of Research in Personality, 31(4), 588-599. https://doi.org/10.1006/jrpe.1997.2204 
Holt-Lunstad, J., Smith, T. B., \& Layton, J. B. (2010). Social relationships and mortality risk: A meta-analytic review. PLoS Medicine, 7(7). https://doi.org/10.1371/journal.pmed.1000316

Hudson, N. W., \& Fraley, R. C. (2017). Adult attachment and perceptions of closeness. Personal Relationships, 24(1), 17-26. http://doi.org/10.1111/pere.12166

Hyun, N. K., Park, Y., \& Park, S. W. (2016). Narcissism and gift giving: Not every gift is for others. Personality and Individual Differences, 96, 47-51. https://doi.org/10.1016/j.paid.2016.02.057

Jackman, M. R. (1994). The velvet glove: Paternalism and conflict in gender, class, and race relations. The University of California Press. https://doi.org/10.2307/2076034

Jamovi. Released 2020. jamovi (Version 1.2) [Computer Software]. https://www.jamovi.org Jones, K., Stewart, K., King, E., Morgan, W. B., Gilrane, V., \& Hylton, K. (2014). Negative consequence of benevolent sexism on efficacy and performance. Gender in Management, 29(3), 171-189. http://doi.org/10.1108/GM-07-2013-0086

Jost, J. T., \& Banaji, M. R. (1994). The role of stereotyping in system-justification and the production of false consciousness. British Journal of Social Psychology, 33(1), 1-27. https://doi.org/10.1111/j.2044-8309.1994.tb01008.x

Jost, J. T., \& Kay, A. C. (2005). Exposure to benevolent sexism and complementary gender stereotypes: Consequences for specific and diffuse forms of system justification. Journal of Personality and Social Psychology, 88(3), 498-509. http://doi.org/10.1037/0022-3514.88.3.498

Kaiser, H. F. (1960). The application of electronic computers to factor analysis. Educational and Psychological Measurement, 20, 141-151.

Katz, J., Merrilees, C., LaRose, J., \& Edgington, C. (2018). White female bystanders' responses to a black woman at risk for sexual assault: Associations with attitudes 
about sexism and racial injustice. Journal of Aggression, Maltreatment \& Trauma, 27(4), 444-459. https://doi.org/10.1080/10926771.2017.1376238

Kenny, D. A. (1996). Models of non-independence in dyadic research. Journal of Social and Personal Relationships, 13(2), 279-294. https://doi.org/10.1177/0265407596132007

Kilianski, S. E., \& Rudman, L. A. (1998). Wanting it both ways: Do women approve of benevolent sexism? Sex Roles, 39(5), 333-352. https://doi.org/10.1023/A:1018814924402

Kirkman, M. S., \& Oswald, D. L. (2019). Is it just me, or was that sexist? The role of sexism type and perpetrator race in identifying sexism. The Journal of Social Psychology. https://doi.org/10.1080/00224545.2019.1634505

Lamy, L., Fischer-Lokou, J., \& Gueguen, N. (2009). Induced reminiscence of love and chivalrous helping. Current Psychology, 28, 202-209. https://doi.org/10.1007/s12144009-9059-9

Leone, R. M., Schipani-McLaughlin, A. M., Haikalis, M., \& Parrott, D. J. (2020). The "white knight" effect: Benevolent sexism accounts for bystander intervention in party situations among high status men. Psychology of Men and Masculinities. https://doi.org/10.1037/men0000314

Lowyck, B., Luyten, P., Demyttenaere, K., \& Corveleyn, J. (2008). The role of romantic attachment and self-criticism and dependency for the relationship satisfaction of community adults. Journal of Family Therapy, 30(1), 78-95. https://doi.org/10.1111/j.1467-6427.2008.00417.x

Masser, B. M., \& Abrams, D. (2004). Reinforcing the glass ceiling: The consequences of hostile sexism for female managerial candidates. Sex Roles, 51(9), 609-615. https://doi.org/10.1007/s11199-004-5470-8 
McMahon, J. M., Kahn, K. B. (2016). Benevolent racism? The impact of target race on ambivalent sexism. Group Processes and Intergroup Relations, 19(2), 169-183. https://doi.org/10.1177/1368430215583153

Morris, D. (1982). Attachment and Intimacy. In M. Fischer \& G. Stricker (Eds.), Intimacy (pp. 305-323). Springer. https://doi.org/10.1007/978-1-4684-4160-4_19

Moulds, E. F. (1980). Chivalry and paternalism: Disparities of treatment in the criminal justice system. In S. Datesman \& F. Scarpitti (Eds.), Women, crime, and justice (pp. 275-299). Oxford Press.

Moya, M., Glick, P., Expósito, F., de Lemus, S., \& Hart, J. (2007). It's for your own good: Benevolent sexism and women's reactions to protectively justified restrictions. Personality and Social Psychology Bulletin, 33(10), 1421-1434. https://doi.org/10.1177/0146167207304790

Nadler, A. (1997). Personality and help seeking: Autonomous versus dependent seeking of help. In G. R. Pierce, B. Lakey, I. G. Sarason, \& B. R. Sarason (Eds.), Sourcebook of social support and personality (pp. 379-407). Plenum Press. https://doi.org/10.1007/978-1-4899-1843-7_17

Nadler, A. (2002). Inter-group helping relations as power relations: Maintaining or challenging social dominance between groups through helping. Journal of Social Issues, 58(3), 487-502. https://doi.org/10.1111/1540-4560.00272

Nadler, A., \& Chernyak-Hai, L. (2014). Helping them stay where they are: Status effects on dependency/autonomy-oriented helping. Journal of Personality and Social Psychology, 106(1), 58-72. https://doi.org/10.1037/a0034152

Napier, J. L., Thorisdottir, H., \& Jost, J. T. (2010). The joy of sexism? A multinational investigation of hostile and benevolent justifications for gender inequality and their 
relations to subjective well-being. Sex Roles, 62(7-8), 405-419. http://doi.org/10.1007/s11199-009-9712-7

Newsom, J. T., Rook, K. S., Sorkin, D. H., \& Mahan, T. L. (2005). Understanding the relative importance of positive and negative social exchanges: Examining specific domains and appraisals. The Journals of Gerontology Series B: Psychological Sciences and Social Sciences, 60(6), 304-312. https://www.ncbi.nlm.nih.gov/pmc/articles/PMC3833824/

Overall, N. C., \& Cross, E. J. (2019). Attachment insecurity and the regulation of power and dependence in intimate relationships. In C. R. Agnew (Ed.), Power in close relationships (pp. 28-54). https://doi.org/10/1017/9781108131490.003

Overall, N. C., Girme, Y., Lemay, E. P., \& Hammond, M. D. (2014). Attachment anxiety and reactions to relationship threat: The benefits and costs of inducing guilt in romantic partners. Journal of Personality and Social Psychology, 106(2), 235-256. https://doi.org/ 10.1037/a0034371

Overall, N. C., Hammond, M. D., McNulty, J. K., \& Finkel, E. J. (2016). When power shapes interpersonal behaviour: Low relationship power predicts men's aggressive responses to low situational power. Journal of Personality and Social Psychology, 111(2), 195217. https://doi.org/10.1037/pspi0000059

Overall, N. C., \& Sibley, C. G. (2009). Attachment and dependence regulation within daily interactions with romantic partners. Personal Relationships, 16(2), 239-261. https://doi.org/10.1111/j.1475-6811.2009.01221.x

Overall, N. C., Sibley, C. G., \& Tan, R. (2011). The costs and benefits of sexism: Resistance to influence during relationship conflict. Journal of Personality and Social Psychology, 101(2), 271-290. http://doi.org/10.1037/a0022727 
Papp, L. J., Liss, M., Erchull, M. J., \& Godfrey, H. (2017). The dark side of heterosexual romance: Endorsement of romantic beliefs relates to intimate partner violence. Sex Roles, 76(1-2), 99-109. https://doi.org/10.1007/s11199-016-0668-0

Ramos, M., Barreto, M., Ellemers, N., Moya, M., \& Ferreira, L. (2018). What hostile and benevolent sexism communicate about men's and women's warmth and competence. Group Processes \& Intergroup Relations, 21(1), 159-177. http://doi.org/10.1177/1368430216656921

Reblin, M., \& Uchino, B. N. (2008). Social and emotional support and its implication for health. Current Opinion in Psychiatry, 21(2), 201-205. https://doi.org/10.1097/YCO.0b013e3282f3ad89

Reis, H. T., \& Carmichael, C. L. (2006). Perceived partner responsiveness scale (PPRS). In D. L. Worthington \& G. D. Bodie (Eds.), The sourcebook of listening research: Methodology and measures (pp. 516-521). Wiley Blackwell.

Reis, H. T., \& Franks, P. (1994). The role of intimacy and social support in health outcomes: Two processes or one? Personal Relationships, 1(2), 185-197. https://doi.org/10.1111/j.1475-6811.1994.tb00061.x

Rosenberg, M. (1965). Society and the adolescent self-image. Princeton University Press. Rudman, L. A., \& Fetterolf, J. C. (2014). How accurate are metaperceptions of sexism? Evidence for the illusion of antagonism between hostile and benevolent sexism. Group Processes \& Intergroup Relations, 17(3), 275-285. https://doi.org/10.1177/1368430213517272

Rudman, L. A., \& Heppen, J. B. (2003). Implicit romantic fantasies and women's interest in personal power: A glass slipper effect? Personality and Social Psychology Bulletin, 29(11), 1357-1370. https://doi.org/10.1177/0146167203256906 
Russo, S., Rutto, F., \& Mosso, C. (2014). Benevolent sexism toward men: Its social legitimation and preference for male candidates. Group Processes \& Intergroup Relations, 17(4), 465-473. http://doi.org/10.1177/1368430213510571

Ryan, R. M., \& Deci, E. L. (2000). Self-determination theory and the facilitation of intrinsic motivation, social development, and well-being. American Psychologist, 55(1), 6878. https://doi.org/10.1037/0003-066X.55.1.68

Shnabel, N., Bar-anan, Y., Kende, A., Bareket, O., \& Lazar, Y. (2016). Help to perpetuate traditional gender roles: Benevolent sexism increases engagement in dependencyoriented cross-gender helping. Journal of Personality and Social Psychology, 110(1), 55. http://doi.org/10.1037/pspi0000037

Simpson, J. A., Rholes, W. S., \& Nelligan, J. S. (1992). Support seeking and support giving within couples in an anxiety-provoking situation: The role of attachment styles. Journal of Personality and Social Psychology, 62(3), 434-446. https://doi.org/10.1037/0022-3514.62.3.434

Simpson, J. A., Rholes, W. S., \& Phillips, D. (1996). Conflict in close relationships: An attachment perspective. Journal of Personality and Social Psychology, 71(5), 899914. http://doi.org/10.1037/0022-3514.71.5.899

Snapp, S., Lento, R., Ryu, E., \& Rosen, K. S. (2014). Why do they hook up? Attachment style and motives of college students. Personal Relationships, 21(3), 468-481. http://doi.org/10.1111/pere.12043

SPSS. Released 2020. IBM SPSS Statistics for Windows (Version 27.0). [Computer Software]. IBM Corp.

Sternberg, R. J. (1997). Construct validation of a triangular love scale. European Journal of Social Psychology, 27(3), 313-335. https://doi.org/10.1002/(SICI)10990992(199705)27:3<313::AID-EJSP824>3.0.CO;2-4 
Stronge, S., Overall, N. C., \& Sibley, C. G. (2019). Gender differences in the associations between relationship status, social support, and wellbeing. Journal of Family Psychology, 33(7), 819-829. https://doi.org/10.1037/fam0000540

Tran, S., \& Simpson, J. A. (2009). Prorelationship maintenance behaviors: The joint roles of attachment and commitment. Journal of Personality and Social Psychology, 97(4), 685-698. http://doi.org/10.1037/a0016418

Uchino, B. N. (2004). Social support and physical health: Understanding the health consequences of relationships. Yale University Press. https://doi.org/10.12987/yale/9780300102185.001.0001

Uchino, B. N. (2006). Social support and health: A review of physiological processes potentially underlying links to disease outcomes. Journal of Behavioral Medicine, 29(4), 377-387. https://doi.org/10.1007/s10865-006-9056-5

Vancouver, J. B., \& Carlson, B. W. (2015). All things in moderation, including tests of mediation (at least some of the time). Organisational Research Methods, 18(1), 7091. https://doi.org/10.1177/1094428114553059

Viki, G. T., \& Abrams, D. (2002). But she was unfaithful: Benevolent sexism and reactions to rape victims who violate traditional gender role expectations. Sex Roles, 47(5-6), 289-293. https://doi.org/10.1023/A:102134912248

Viki, G. T., Abrams, D., \& Hutchison, P. (2003). The "true" romantic: Benevolent sexism and paternalistic chivalry. Sex Roles, 49(9), 533-537. https://doi.org/10.1023/A:1025888824749

Viki, G. T., Massey, K., \& Masser, B. (2005). When chivalry backfires: Benevolent sexism and attitudes toward Myra Hindley. Legal and Criminological Psychology, 10(1), 109-120. https://doi.org/10.1348/135532504X15277 
Weiner, B. (1980). A cognitive (attribution)-emotion-action model of motivated behaviour: An analysis of judgments of help-giving. Journal of Personality and Social Psychology, 39(2), 186-200. https://doi.org/10.1037/0022-3514.39.2.186

Weinstein, N., \& Ryan, R. M. (2010). When helping helps: Autonomous motivation for prosocial behavior and its influence on well-being for the helper and recipient. Journal of Personality and Social Psychology, 98(2), 222-244. https://doi.org/10.1037/a0016984

Wickham, R. E., \& Knee, C. R. (2012). Interdependence theory and the actor-partner interdependence model: Where theory and method converge. Personality and Social Psychology Review, 16(4), 375-393. https://doi.org/10.1177/1088868312447897

Yoder, J. D., Hogue, M., Newman, R., Metz, L., \& LaVigne, T. (2002). Exploring moderators of gender differences: Contextual differences in door-holding behaviour. Journal of Applied Social Psychology, 32(8), 1682-1686. https://doi.org/10.1111/j.1559-1816.2002.tb02769.x

Young, D. M., Beier, E. G., Beier, P., \& Barton, C. (1975). Is chivalry dead? Journal of Communication, 25(1), 57-64. http://doi.org/10.1111/j.1460-2466.1975.tb00554.x 